\title{
Characteristics of the community-structure of A20 processes under different temperature conditions in plateau areas
}

\section{Yongchen Zong}

Tibet Agriculture and Husbandry University

\section{Yuanwei Li}

Tibet Agriculture and Husbandry University https://orcid.org/0000-0001-9506-3589

\section{Decai Huang}

Tibet Agriculture and Animal Husbandry University

Kaiyue Hao

Tibet Agriculture and Animal Huabandry University

Guanghua Lu ( $\nabla 3588416157 @ q q . c o m$ )

Tibet Agriculture and Husbandry University

\section{Research article}

Keywords: plateau area, temperature, 16SrRNA sequencing, anaerobic-anoxic-aerobic (A20) processes, community structure

Posted Date: July 28th, 2020

DOI: https://doi.org/10.21203/rs.3.rs-45362/v1

License: (c) (i) This work is licensed under a Creative Commons Attribution 4.0 International License. Read Full License 


\title{
Characteristics of the community-structure of $\mathrm{A} 2 \mathrm{O}$ processes
}

\section{under different temperature conditions in plateau areas}

\author{
ZONG Yongchen ${ }^{1,2,3,4,5,6}$,LI Yuanwei ${ }^{6}$, HUANG Decai ${ }^{6}$, HAO Kaiyue ${ }^{6}$ and LU \\ Guanghua $^{* 1,2,3,4,5,6}$
}

\begin{abstract}
Background: In this study, laboratory-scale $\mathrm{A} 2 \mathrm{O}$ wastewater treatment was performed in Linzhi at an altitude of 3000 meters. Water temperatures were maintained at four operating conditions $\left(25^{\circ} \mathrm{C}\right.$, $20^{\circ} \mathrm{C}, 15^{\circ} \mathrm{C}$, and $10^{\circ} \mathrm{C}$ ). Sludge in the aerobic tank was assessed by $16 \mathrm{SrRNA}$ sequencing and composition analysis. The Phylum, Class, Order, Family, Genus, and Species of the sludge were also confirmed.
\end{abstract}

Results: The bacteria within the sludge showed significant differences at varying temperatures $(\mathrm{P}<0.05)$. A significant correlation between the bacteria numbers in anaerobic tanks and anoxic tanks also occurred. Indicators of community richness, community uniformity, community diversity and other areas showed differences. Significant differences in bacteria abundance were also observed and differed to those of previously reported superior community categories and proportions. T-tests were used to identify temperature-sensitive community at each level. Correlation analysis of environmental factors and colony structure further confirmed the association between temperature and colony structure $(\mathrm{P}<0.05)$. The removal rates of $\mathrm{TP}, \mathrm{TN}, \mathrm{NH}_{3}-\mathrm{N}$, and $\mathrm{COD}$ were all affected by the sample community structure. The variety of colony structure include nitrifying bacteria, denitrifying bacteria, phosphorus accumulating bacteria and other bacterial differed, but their proportions were relatively low. Heatmaps were used to identify species sensitive to temperature, TP, TN, $\mathrm{NH}_{3}-\mathrm{N}, \mathrm{COD}$ at the species level.

Conclusions: Amongst the common dominant bacteria at the species level, Bacteroidetes_bacterium_OLB10 was significantly related to temperature. Other common dominant bacteria that were related to temperature metagenome_g_Gordonia, unclassified_f_Burkholderiaceae, uncultured_bacterium_g_norank_f_Saprospiraceae.

Keywords: plateau area; temperature; 16SrRNA sequencing; anaerobic-anoxic-aerobic (A2O) processes; community structure.

\section{Background}

As the third pole, the Qinghai-Tibet Plateau has an average altitude of more than 4000 meters. The high altitude creates unique environmental conditions of high cold and low air pressure. In recent years, Tibet has amassed a large number of urban sewage treatment plants, but their operating conditions are unsatisfactory, mainly due to the poor effects of nitrogen and phosphorus removal because of the unique environment conditions(Zong et al., 2019).

According to measurements, the summer water temperature in Changdu City at an altitude of 3500 meters is $12.2 \sim 18.5^{\circ} \mathrm{C}$ (Zhai et al., 2012) compared to the water temperature of Linzhi City at an altitude of 3000 meters is $-1 \sim 15^{\circ} \mathrm{C}$ (Chen et al., 2018). Studies have shown that the water temperature in Tibet is low, which impacts the microbial structure of the sewage treatment system and the effects of nitrogen and phosphorus removal (Zong et al., 2019). Tian et al. (Tian et al., 2015) identified 51,880 genus microorganisms from the activated sludge ecosystem of municipal sewage 
treatment plants using the $\mathrm{A} 2 \mathrm{O}$ process, including Proteus, Bacteroides, Nitrospira and Green Campylobacter as the dominant bacteria. In view of the large differences in microbial colony structures at different water temperatures, numerous studies on water temperature and microbial structure have been performed. Using biological aerated filters, Dou and colleagues (Dou et al., 2016) reported that when the temperature was lower than $18{ }^{\circ} \mathrm{C}$ (low temperature), the removal rate of COD and $\mathrm{NH}_{3}-\mathrm{N}$ of the biological aerated filters were less than $60 \%$. The structure of the flora in the tank was simple, and the density of the flora decreased. The activity and quantity of enriched phosphorus accumulating bacteria showed a decreasing trend at increasing temperatures, but when the temperature decreased, the activity of phosphorus accumulating bacteria Acinetobacter enhanced its phosphorus removal effect (Fang et al., 2011). Ma and coworkers (Ma et al., 2020) assessed induced temperature periodic changes. They found that the activity a50nd relative abundance of ammonia oxidizing bacteria, nitrite oxidizing bacteria, and anammox bacteria, were dominated by Candidatus Brocadia at low temperatures, which changed following periodic temperature shocks. The formation of dissolved organic nitrogen was also influenced by both microbial activity and microbial community structure (Liao et al., 2019). The performance and stabilization of biological wastewater treatment systems are also closely related to the microbial community structure, variations in which are driven by temperature (Chen et al., 2017). Decreased temperatures result in significant reductions in microbiome diversity, and the alpha diversity of the active community (Paul et al., 2020). Upon analysis of the capacity of nitrogen removal and the spatial distribution of microbial communities at low temperatures, it was shown that low temperatures inhibit nitrogen removal (Paul et al., 2020). It is therefore clear that temperature changes impact microbial structure in wastewater treatment processes and the quality of wastewater treatment water.

Microbial composition and changes in $\mathrm{A} 2 \mathrm{O}$ processes under different temperature conditions are typical characteristics of the community structure. This must be explored to fully understand microbial response mechanisms under the influence of plateau environmental factors, and provides a theoretical system for sewage biological treatment systems affected by plateau environmental factors. In this study, we selected the $\mathrm{A} 2 \mathrm{O}$ system as a typical sewage treatment process to analyze the influence of temperature conditions. We assessed community structure characteristics and their alterations in anoxic and aerobic regions to explore the microbial response mechanisms influenced by plateau environmental factors.

\section{Methods}

The A2O system was selected as a typical sewage treatment process. Microbial structure characteristics were explored to investigate the influence of low temperature at a range of environmental factors. We further explored the performance of experimental scale $\mathrm{A} 2 \mathrm{O}$ processes in response to a range of plateau environmental factors..

\subsection{Experimental setup}


Laboratory-scale A2O sewage treatment devices were produced from Plexiglas. Each device had an effective volume of $210 \mathrm{~L}$ and was divided into 3 compartments; (1) an anaerobic tank; (2) an anoxic tank; (3) an aerobic tank. The volume ratio of the three regions were 35:58:117, and the effective volume of the sedimentation tank was $39 \mathrm{~L}$. Both the anaerobic and anoxic tank were equipped with a stirring device at a stirring speed of $50 \mathrm{rpm}$. The aerobic tank was equipped with an aeration head for the oxygen supply. A peristaltic pump was used to control the inlet water, return sludge and nitrification liquid. To ensure constant temperatures in the test, a constant temperature circulator was used to control the water temperature. Each tank wall had a sampling port. The specific device processes are shown in Figure 1.

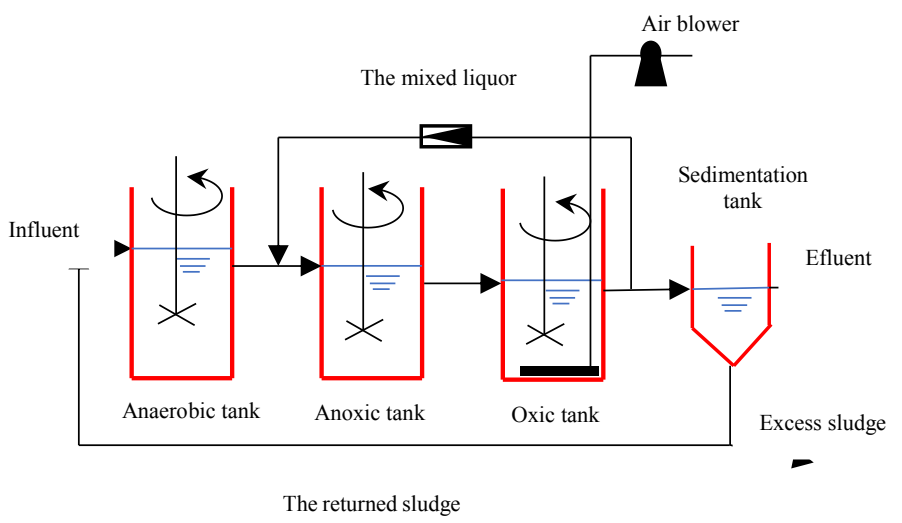

Figure 1. Schematic of Anaerobic-Anoxic-Oxic process

After 35 days of activated sludge culture, the temperature was controlled at $20.0^{\circ} \mathrm{C}$, the $\mathrm{SV}_{30}$ was $34 \%$, and the MLSS was $4325 \mathrm{mg} / \mathrm{L}$. We used urban sewage in Linzhi City as the test water, the quality status of which is shown in Table 1.

Table 1. Quality indicators of Sewage

\begin{tabular}{cccc}
\hline potential of Hydrogen & $\begin{array}{c}\text { Chemical Oxygen Demand } \\
(\mathrm{mg} / \mathrm{L})\end{array}$ & Total Nitrogen $(\mathrm{mg} / \mathrm{L})$ & $\begin{array}{c}\text { Total Phosphorous } \\
(\mathrm{mg} / \mathrm{L})\end{array}$ \\
\hline $8.79-9.04$ & $92.95 \sim 530.62$ & $38.725 \sim 186.775$ & $2.075 \sim 14.325$ \\
\hline
\end{tabular}

\subsection{A2O Operation}

A2O processes at each temperature were investigated. The designed inlet flow rate was $10.0 \pm$ $0.1 \mathrm{~L} / \mathrm{s}$. The aerobic tank had a dissolved oxygen content of $2 \mathrm{mg} / \mathrm{L}$. The hydraulic retention time was $21.0 \pm 0.2 \mathrm{~h}$, the anaerobic tank residence time: anoxic tank residence time: and aerobic tank residence time were 35:58:117. The reflux ratio of the mixed solution was $\mathrm{RI}=200 \%$. The reflux ratio of the sludge was $\mathrm{R}=100 \%$. Both the mixed solution and sludge were continuously refluxed. Changes in dissolved oxygen were achieved through altering the levels of blown aeration. Controls were set to four levels of $25{ }^{\circ} \mathrm{C}, 20{ }^{\circ} \mathrm{C}, 15{ }^{\circ} \mathrm{C}$, and $10{ }^{\circ} \mathrm{C}$. Sampling was performed 72 hours after the temperature reached the designed value.

\section{Results and discussion}

Microbiological indicators were compared using SPSS 20.0 and are expressed as the mean \pm standard deviation (SD). A one-way analysis of variance (ANOVA) to assess significant differences. $\mathrm{P}<0.05$ (Simon et al., 1989) indicated significant differences between samples.

Anaerobic, anoxic and aerobic tank sludge were sampled at each temperature and 16SrRNA sequencing was performed.

\subsection{Basic information}

Taxonomic analysis of the domain, kingdom, phylum, class, order, family, genus and species 
of each sample were assessed. Operational Taxonomic Units (OTU) were identified using the Silva database. The statistical results of specific samples are shown in Table 2.

Table 2. Sample information

\begin{tabular}{cccccccccc}
\hline Sample & Domain & Kingdom & Phylum & Class & Order & Family & Genus & Species & OTU \\
\hline temp_ana_25 & 1 & 1 & 20 & 35 & 97 & 188 & 376 & 533 & 734 \\
temp_ana_20 & 1 & 1 & 27 & 52 & 126 & 234 & 477 & 707 & 969 \\
temp_ana_15 & 1 & 1 & 29 & 56 & 134 & 241 & 505 & 757 & 1067 \\
temp_ana_10 & 1 & 1 & 30 & 54 & 131 & 239 & 453 & 664 & 898 \\
temp_ano_25 & 1 & 1 & 24 & 41 & 103 & 198 & 413 & 607 & 849 \\
temp_ano_20 & 1 & 1 & 27 & 47 & 123 & 235 & 491 & 712 & 970 \\
temp_ano_15 & 1 & 1 & 29 & 53 & 131 & 242 & 493 & 745 & 1028 \\
temp_ano_10 & 1 & 1 & 28 & 52 & 129 & 239 & 455 & 675 & 908 \\
temp_Oxic_25 & 1 & 1 & 27 & 44 & 103 & 194 & 394 & 567 & 772 \\
temp_Oxic_20 & 1 & 1 & 27 & 50 & 126 & 238 & 471 & 678 & 911 \\
temp_Oxic_15 & 1 & 1 & 26 & 43 & 102 & 193 & 379 & 560 & 758 \\
temp_Oxic_10 & 1 & 1 & 27 & 49 & 121 & 225 & 426 & 625 & 837 \\
\hline
\end{tabular}

Only a single Domain and Kingdom were investigated through sequencing, and Phylum $\in$ (20,30), Class $\in(35,56)$, Order $\in(97,134)$, Family $\in(188,242)$, Genus $\in(376,505)$, Species $\in(533,757)$, OTU $\in(734,1067)$, and the corresponding genealogical values were significantly lower than those stated in the literature. At the Phylum level, values were similar to the 24 reported by Sun and colleagues (sun et al., 2019), but were lower than the value of 51 recorded by Tian and coworkers (Tian et al., 2015). At the Genus level, the values were also lower than the Tian study (Tian et al. ., 2015). The value of the test 800 was low. At the OUT level, the values (924 1363) were comparable to Wen and colleagues (Wen et al., 2015) in the SBR process, but exceeded those of Jin and coworkers (Jin et al. ., 2017; Zhang et al., 2019; Fan et al., 2018). Upon measurement of the A/O processes, the aerobic tank had low OUT values. Previous studies suggest that the temperature of the Phylum, Class, Order, and Family levels significantly influence the number of species $(\mathrm{P}<0.05)$. Compared to previous studies, we observed large differences in the number of microbial species, particularly at the temperature of the plateau, variations in which significantly influenced the number of bacteria at the Phylum, Class, Order, and Family levels. In addition, correlation analysis revealed significant differences in the number of species of phylum, phylum, order, family, genus and species at each temperature $(\mathrm{P}<0.05)$. The number of phylum, phylum, order, family, genus and species also differed. A significant correlation between the anaerobic tank and anoxic tank were observed $(\mathrm{P}<0.05)$. No significant correlation between the aerobic tank and the above two reactors $(\mathrm{P} \geq 0.05)$ were observed. There were no obvious correlations between the number of genus, order, family, genus and species $(\mathrm{P} \geq 0.05)$.

\subsection{Alpha diversity analysis}

The Alpha diversity comprises the diversity index and the differences between index groups. The commonly used metrics of the index are chao (colony richness), shannoneven (colony uniformity), ace (colony richness), Simpson (colony diversity), and coverage (colony coverage). $\mathrm{T}$ tests were performed to detect significant correlations between the two groups. The diversity index of each sample are shown in Table 3. 
Table 3. Alpha Diversity Statistics Table

\begin{tabular}{cccccc}
\hline Sample & shannoneven & ace & chao & coverage & simpson \\
\hline temp_ana_25 & 0.686311 & 678.636 & 672.000 & 0.996 & 0.063589 \\
temp_ana_20 & 0.700519 & 867.345 & 904.167 & 0.996 & 0.028344 \\
temp_ana_15 & 0.643979 & 902.975 & 912.556 & 0.996 & 0.02355 \\
temp_ana_10 & 0.613907 & 866.421 & 892.741 & 0.994 & 0.064387 \\
temp_Oxic_25 & 0.619765 & 720.442 & 726.797 & 0.996 & 0.045108 \\
temp_Oxic_20 & 0.656817 & 839.848 & 839.318 & 0.995 & 0.032669 \\
temp_Oxic_15 & 0.688048 & 925.187 & 882.961 & 0.995 & 0.062754 \\
temp_Oxic_10 & 0.661908 & 816.326 & 844.380 & 0.995 & 0.08789 \\
temp_ano_25 & 0.710761 & 785.327 & 818.406 & 0.996 & 0.042694 \\
temp_ano_20 & 0.645525 & 884.870 & 911.405 & 0.996 & 0.029929 \\
temp_ano_15 & 0.626017 & 910.082 & 875.190 & 0.995 & 0.032413 \\
temp_ano_10 & 0.68918 & 876.520 & 862.011 & 0.994 & 0.063279 \\
\hline
\end{tabular}

The community coverage (Wang et al., 2019) has an overage coefficient of $0.994 \sim 0.996$, with all exceeding 0.990 . The sample sequencing coverage was good, meaning the probability that the sample sequence not being detected was extremely low. The ace coefficient of community richness was 678.6 925.2 which was comparable to previous studies (Chen et al., 2018; Zhang et al., 2019). Ace values were $1300 \sim 2200$ and $1038 \sim 1159$. Low levels of community uniformity were observed with a Shannon coefficient of $0.613907 \sim 0.710761$, which was lower than previously reported values ( $\mathrm{Li}$ et al., 2014). The community diversity measured as the Simpson coefficient was $0.02355 \sim 0.08789$ in previous studies (Zhang et al., 2019). The Shannon coefficient was $0.935-$ 0.976 which was comparable to Chen and colleagues (Chen et al., 2018) who reported values of 0.835 .

Upon assessment of the four operating conditions: excluding operating conditions of $10^{\circ} \mathrm{C}$ and $20^{\circ} \mathrm{C}$, there were significant differences in the ace coefficient of community richness between each of the operating conditions $(\mathrm{p} \leq 0.05)$. There were significant differences in the number of species except for at $10^{\circ} \mathrm{C}$ and $20^{\circ} \mathrm{C}$. The community diversity measured through the Simpson coefficient differed between $10^{\circ} \mathrm{C}$ and $20^{\circ} \mathrm{C}, 10^{\circ} \mathrm{C}$ and $15^{\circ} \mathrm{C}$, and $20^{\circ} \mathrm{C}$ and $25^{\circ} \mathrm{C}(\mathrm{p}<0.05)$; Significance analysis of the community richness chao coefficient revealed significant differences between $10^{\circ} \mathrm{C}$ and $15^{\circ} \mathrm{C}, 20^{\circ} \mathrm{C}$ and $25^{\circ} \mathrm{C}$, and $15^{\circ} \mathrm{C}$ and $25^{\circ} \mathrm{C}(\mathrm{P}<0.05)$. The Simpson even coefficient of community uniformity also showed significant differences between $10^{\circ} \mathrm{C}$ and $20^{\circ} \mathrm{C}, 10^{\circ} \mathrm{C}$ and $20^{\circ} \mathrm{C}$, and $20^{\circ} \mathrm{C}$ and $25^{\circ} \mathrm{C} \quad(\mathrm{P}<0.05)$. Under the four groups of working conditions, there are were one or more significant differences in community richness, community diversity or community uniformity, suggesting that temperature significantly influences colony structure. Differences in community richness from the aerobic to anoxic tank, oxygen tank and anaerobic tank, and anoxic tank and anaerobic tank were observed. The community diversity varied in both the anaerobic and anoxic tank, anaerobic tank and aerobic tank, and anoxic tank and aerobic tank. Differences in community uniformity were observed upon comparison of anaerobic and anoxic, anoxic and aerobic, and anaerobic and aerobic tanks.

\subsection{Community composition analysis}

The RDPClassifier was used for classification statistics of the three reactors under each of the operating conditions in the order of Domain, Kingdom, Phylum, Class, Order, Family, and Genus. We further focused on the analysis of fungus function at the Genus level, and analyzed each sample. The composition of the middle population when including community with an abundance greater than $1 \%$ of different classification levels showed only a single bacteria at the domain analysis level and no rank_d__Bacteria at the Kingdom analysis level.

\subsubsection{Analysis of the characteristics of colony structure at the Phylum level}




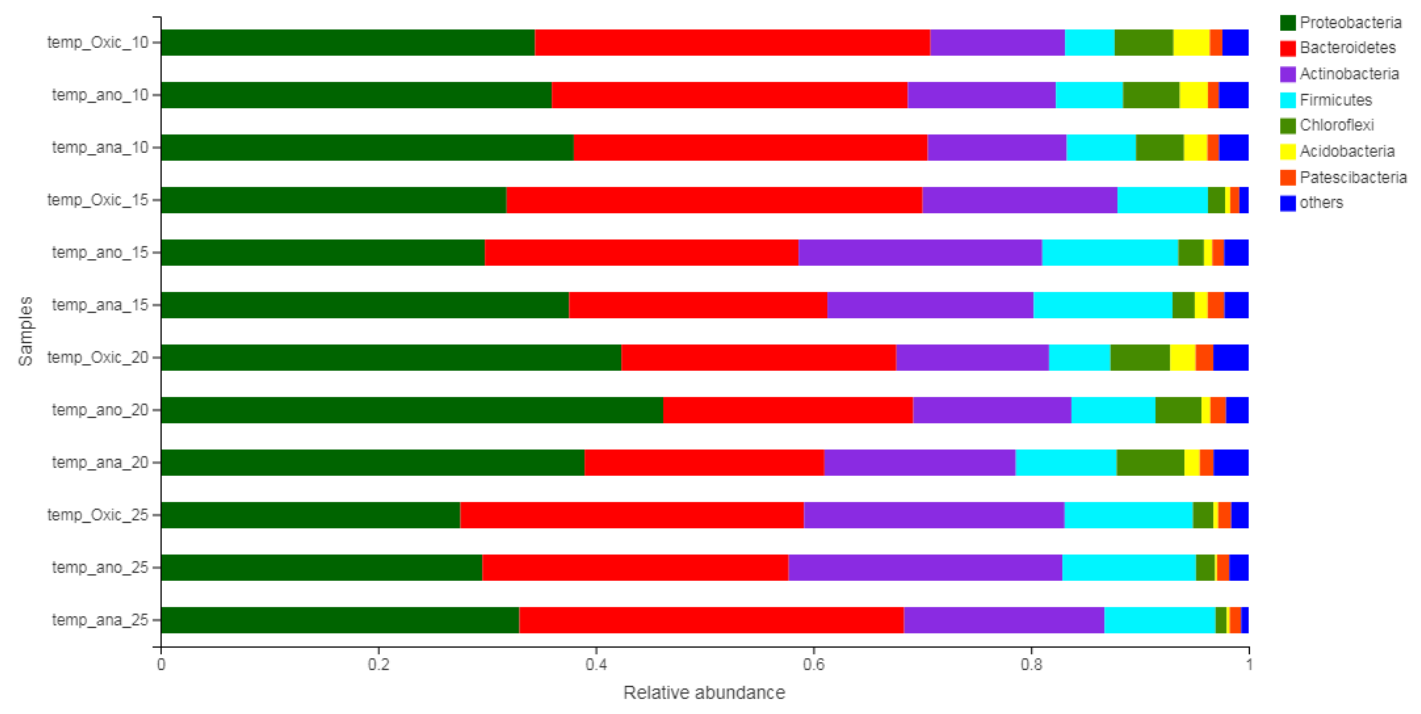

Figure 2. Community composition according to Phylum level

Figure 2 shows that shared dominant communities at the Phylum level were Proteobacteria, Bacteroidetes, Actinobacteria, Firmicutes, and Chloroflexi. A total of 31 Phylums were obtained. The abundance of five of the Phylums were $94.31-99.04 \%$ in the anaerobic and anoxic tanks. The aerobic tank showed a decreasing trend as the temperature decreased. More abundant doors and Firmicutes were observed compared to the literature (Cydzik-Kwiatkowska et al., 2016).

The abundance of Proteobacteria $(27.58 \% \sim 46.22)$ represented a relatively high proportion of organic matter-degrading bacteria. The abundance of Proteobacteria in anaerobic tanks, anoxic tanks, and aerobic tanks gradually decreased, whilst the abundance of Proteobacteria increased. The most abundant gates are consistent with previous studies (Cydzik-Kwiatkowska et al., 2016), but the corresponding abundance was lower than previously reported (Muszyński et al., 2015). The abundance of Bacteroidetes was $21.93 \% \sim 38.25 \%$. This obligate anaerobic phylum can promote the utilization of nitrogen-containing substances and the hydrolysis of macromolecular organic substances. The aerobic tanks had a significantly higher abundance than anaerobic and anoxic tanks. Bacteroidetes were more abundant than those reported by Juretschko et al. (2002) and Kong et al. (2007). The values obtained were low; the abundance of Actinobacteria were $12.33 \%-25.14 \%$ in heterotrophic aerobic phylum, and its change in abundance suggested that the concentration of the anoxic tank exceeded that of the anaerobic tank and oxygen tank. The abundance of Firmicutes was $4.52 \%$ to $12.74 \%$. These are denitrifying bacteria that are mainly present in anoxic conditions. Their abundance in the anaerobic tank was higher, and the abundance of Firmicutes was higher than that reported by Beer et al. (2006), but lower than that reported by Wong et al. (2005). The abundance of Chloroflexi was $1.04 \% \sim 6.26 \%$. These are aerobic sulphur bacteria the abundance of which decreases in anoxic and aerobic tanks as temperature decreases.

The abundance of Proteobacteria, Actinobacteria, Firmicutes and Chloroflexi all differed according to temperature $(\mathrm{P} \leq 0.05)$. Of these four dominant bacteria, the Phylum number had a significant effect, but the dominant strains at the gate level showed no significant differences under different reactors. 


\subsubsection{Analysis of the characteristics of colony structure at the Class level}

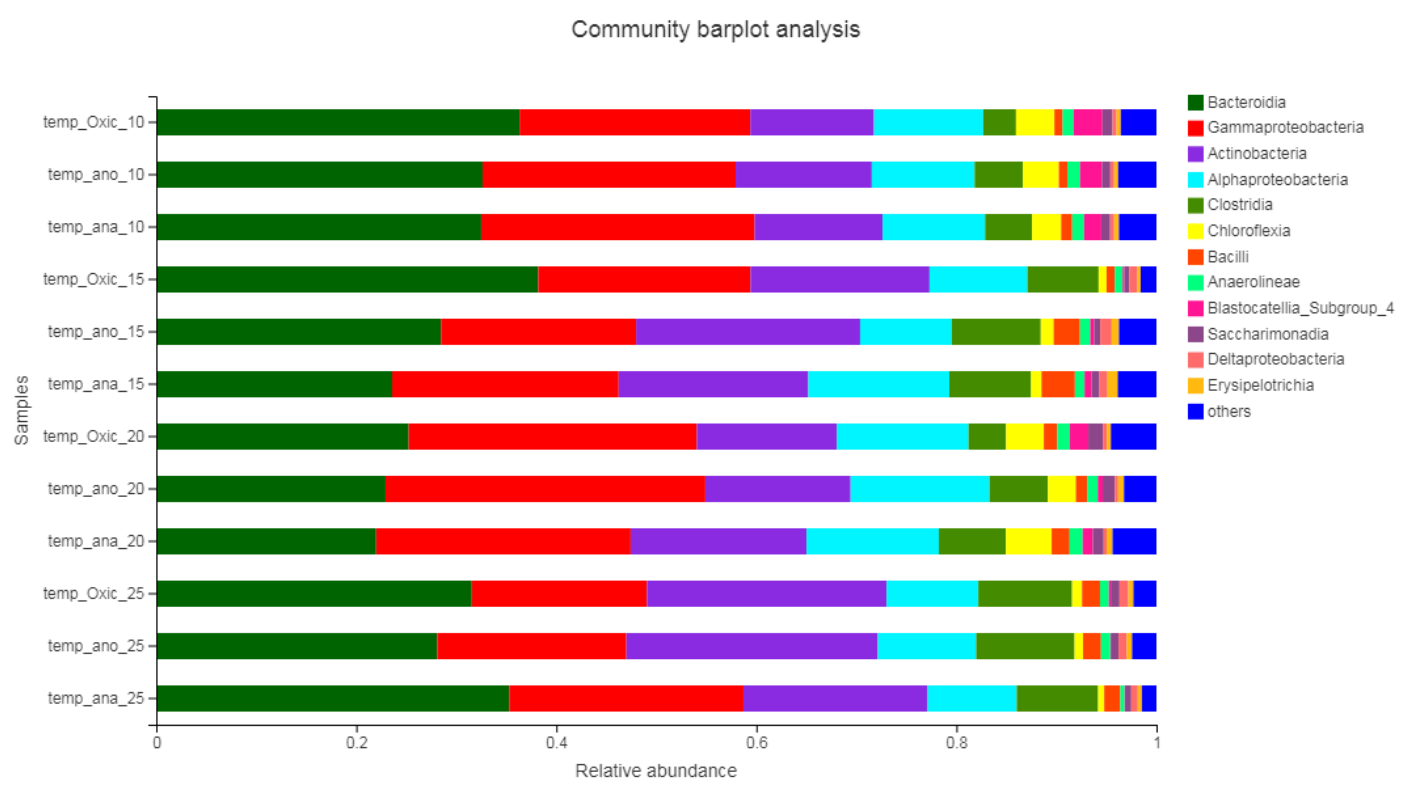

Figure 3. Community composition according to Class level.

Figure 3 shows the five classes of Bacteroidia, Gammaproteobacteria, Actinobacteria, Alphaproteobacteria, Clostridia. A total of 66 Classes were obtained. The abundance of 5 classes were $84.96-94.23 \%$ which showed a decreasing trend in the anoxic tank as temperature decreased. These findings were comparable to previous studies (Cydzik-Kwiatkowska et al., 2016) excluding the $\beta$-proteobacteria values. These findings also differed to Kang and colleagues (Kang et al., 2019) in terms of the type and proportion of dominant strains.

Gammaproteobacteria and Alphaproteobacteria belong to the Proteobacteria phylum and represent denitrifying bacteria. The abundance of Alphaproteobacteria and Gammaproteobacteria were higher than the literature (Muszyński et al., 2015), whilst the abundance of Bataproteobacteria were higher than reported by Nielsen et al. (2012), Wong et al. (2005) and Schmid et al. (2003) Clostridia belongs to the Chloroflexi door, which varies greatly in different reactors under different working conditions. The abundance of Actinobacteria (12.33-25.14\%) was higher than Zhang et al. (2018). The change interval was smaller than Chen et al. (2017) and the abundance of Bacteroidia was larger than Zhang et al. (2018).

Gammaproteobacteria, Actinobacteria, Clostridia were the three dominant bacteria that showed significant differences $(\mathrm{P} \leq 0.05)$ under different temperature conditions. In addition, Chloroflexia $(0.61-4.61 \%)$ and Anaerolineae $(0.42-1.30 \%)$ showed changes in abundance at different temperatures $(\mathrm{P} \leq 0.05)$. Whilst temperature has a significant effect on the number of the above five bacterial community, there no significant differences observed as a result of the different reactors $(\mathrm{P}>0.05)$. 


\subsubsection{Analysis of the characteristics of colony structure at the Order level}

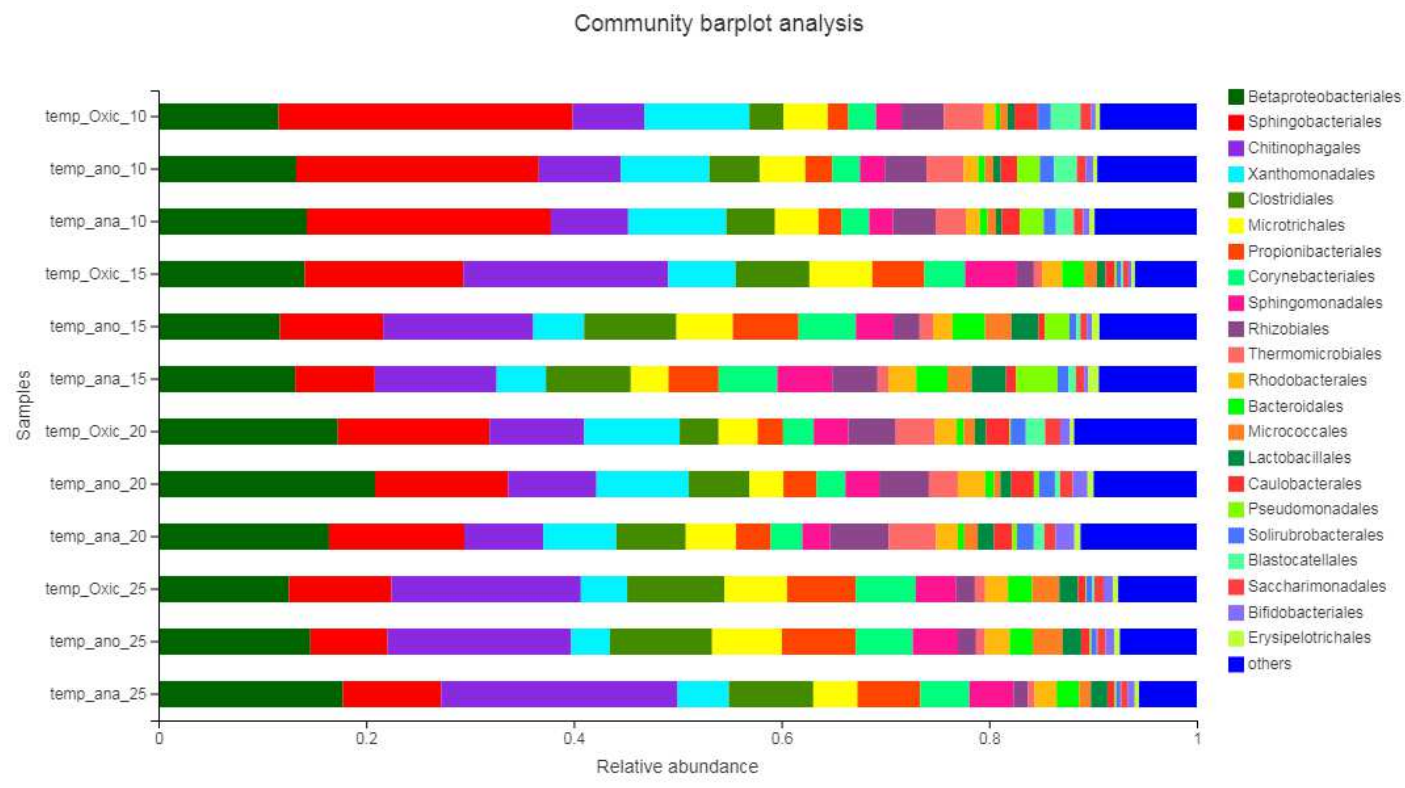

Figure 4. Community composition according to order.

Figure 4 shows that under the above working conditions, the predominant bacterium order were Betaproteobacteriales, Sphingobacteriales, Chitinophagales, Xanthomonadales, Clostridiales, Microtrichales, Propionibacteriales, Corynebacteriales, Sphingomonadales, Rhizobiales, and Rhodobacterales. A total of 168 Orders were obtained. The abundance of 11 Orders were 71.93$86.24 \%$. In addition, the abundance of seven orders of Thermomicrobiales, Bacteroidales, Micrococcales, Lactobacillales, Caulobacterales, Pseudomonadales, and Solirubrobacterales varied greatly. This accounted for $6.77-13.36 \%$ of all bacteria that were sensitive to temperature changes.

The analysis showed that: Microtrichales, Propionibacteriales, Corynebacteriales, Micrococcales, Solirubrobacterales belong to the Actinobacteria phylum. The abundance of Microtrichales and Corynebacteriales were relatively stable, the abundance of Propionibacteriales increased at increasing temperature, and Micrococcales and Solirubrobacterales were relatively unstable at different temperature conditions. Sphingobacteriales, Chitinophagales, and Bacteroidales belong to the Bacteroidetes order. Sphingobacteriales decreased with increasing temperature and were more abundant in the aerobic tank compared to other reactors. Chitinophagales, Bacteroidales are unstable with changes in temperature changes and showed a correlation. Clostridiales, Lactobacillales and Erysipelotrichales belong to the Firmicutes phylum; Betaproteobacteriales, Xanthomonadales, Sphingomonadales, Rhizobiales, Rhodobacterales, Caulobacterales, Pseudomonadales belong to the Proteobacteria phylum. Amongst them, Betaproteobacteriales were more abundant than those of other well-characterised anaerobic bacteria. The proportions of Caulobacterales and Pseudomonadales in anaerobic and anoxic tanks were higher. Betaproteobacteriales tended to increase with increasing temperatures in each reactor and were higher in anaerobic tanks. Xanthomonadales were higher in aerobic tanks and increased with temperature Sphingomonadales and Rhizobiales did not change with temperature or according to the reactor. Rhodobacterales showed an increasing trend with increasing temperature in each reactor. Thermomicrobiales belong to the Chloroflexi door, which was greatly affected by temperature, including at $25^{\circ} \mathrm{C}$. All three reactors were lower (less than 1\%), the aerobic tank was slightly higher 
than $1 \%$ in the anoxic tank and the anaerobic tank at $15^{\circ} \mathrm{C}$.

A total of 8 common dominant bacterial orders of Sphingobacteriales, Chitinophagales, Xanthomonadales, Clostridiales, Propionibacteriales, Corynebacteriales, Sphingomonadales, Rhizobiales showed significant differences under temperature conditions $(\mathrm{P} \leq 0.05)$, and Thermomicrobiales (0.61-4.60\%), Bacteroidales (0.47-3.14\%), Caulobacterales (0.63-2.25\%), Solirubrobacterales (0.41-1.58\%) showed an altered abundance under temperature conditions $(\mathrm{P} \leq 0.05)$. Temperature therefore had a significant effect on these four bacteria. The predominant strains at the order level showed no significant differences in each reactor $(\mathrm{P}>0.05)$.

\subsubsection{Analysis of the characteristics of colony structure at the Family level}

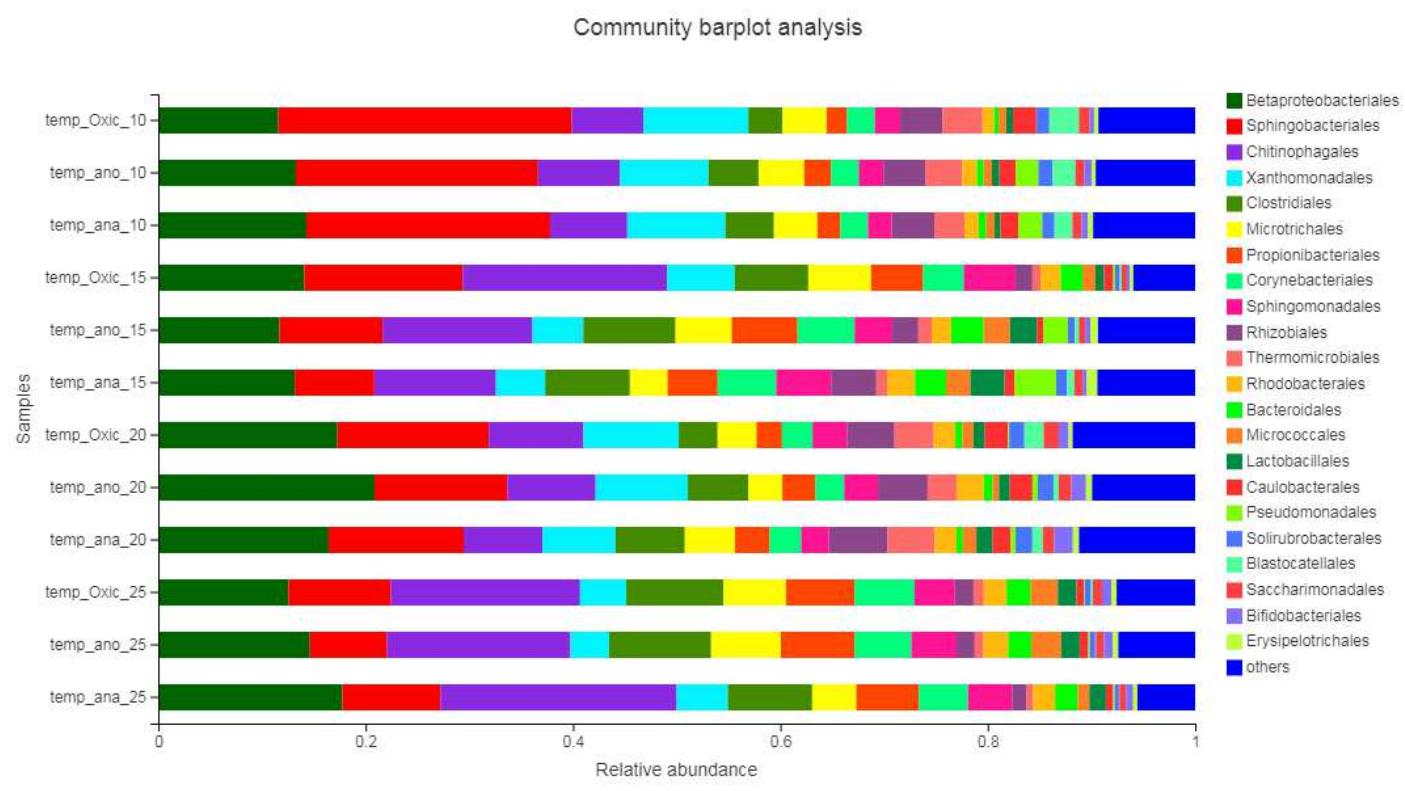

Figure 5. Community composition according to family level.

Figure 5 shows that the dominant fungi were AKYH767, Burkholderiaceae, Saprospiraceae, Microtrichaceae, Propionibacteriaceae, Sphingomonadaceae, Xanthomonadaceae, Rhodanobacteraceae, Chitinophagaceae, Nocardiaceae, Rhodobacteraceae, and Peptostreptocoaceae. A total of 325 Families were obtained. The abundance of 5 Families were 54.98-72.41\%, which were the dominant fungi in the plateau environment. The composition of the dominant bacteria in previous studies (Yang et al., 2017) lack Comamon-adaceae, Nitrospiraceae, Sinobacteraceae, Hyphomicrobiaceae, and Chromatiaceae. It was also important to note that the abundance of nine Families of JG30-KF-CM45, Rhizobiaceae, Clostridiaceae_1, Christensenellaceae, Carnobacteriaceae, Caulobacteraceae, Hydrogenophilaceae, Microbacteriaceae, and Moraxellaceae varied greatly and were more sensitive to temperature.

In addition, Microtrichaceae, Propionibacteriaceae, Nocardiaceae, and Microbacteriaceae belong to Actinobacteria, the abundance of which increased with temperature and were higher in the aerobic tank. AKYH767, Saprospiraceae, and Chitinophagaceae belong to Bacteroidetes, and the abundance of AKYH767 increased with temperature. The aerobic tank showed higher levels of these bacteria than other reactors. The abundance of Saprospiraceae showed an increasing trend with increasing temperature and the aerobic tank was superior to other reactors. The abundance of Chitinophagaceae showed a downward trend with increasing temperature. The reactor was relatively balanced; Peptostreptococcaceae, Clostridiaceae_1, Christensenellaceae, and 
Carnobacteriaceae belong to the Firmicutes family. The abundance of anaerobic tanks of

Peptostreptococcaceae were significantly higher than other reactors. Clostridiaceae_1, Christensenellaceae, Carnobacteriaceae, ceca Xanthomonadaceae, Rhodanobacteraceae, Rhodobacteraceae, Rhizobiaceae, Caulobacteraceae, Hydrogenophilaceae, and Moraxellaceae belong to the Proteobacteria phylum, amongst which Burkholderiaceae and Hydrogenophilaceae belong to Betaproteobacteriales, which are polyphosphate bacteria. JG30-KF-i45 belongs to the Chloroflex and Chloroflexi.

AKYH767, Saprospiraceae, Microtrichaceae, Propionibacteriaceae, Sphingomonadaceae, Xanthomonadaceae, Rhodanobacteraceae, Chitinophagaceae, Nocardiaceae, Rhodobacteraceae were then the 10 common dominant bacteria under temperature conditions $\mathrm{P} \leq 0.05$ ). JG30-KFCM45 (0.42-3.56\%), Rhizobiaceae (0.62-2.84\%), Clostridiaceae_1 (0.77-2.27\%), Christensenellaceae (0.26-3.03\%), Caulobacteraceae (0.63-2.13\%), and Hydrogenophilaceae (0.52$2.89 \%)$ showed changes in abundance according to temperature $(\mathrm{P} \leq 0.05)$. The abundance of Peptostreptococcaceae significantly differed between the reactors $(\mathrm{P} \leq 0.05)$. No other significant differences between bacteria in different reactors were observed $(\mathrm{P}>0.05)$.

\subsubsection{Analysis of the characteristics of colony structure at the Genus level}

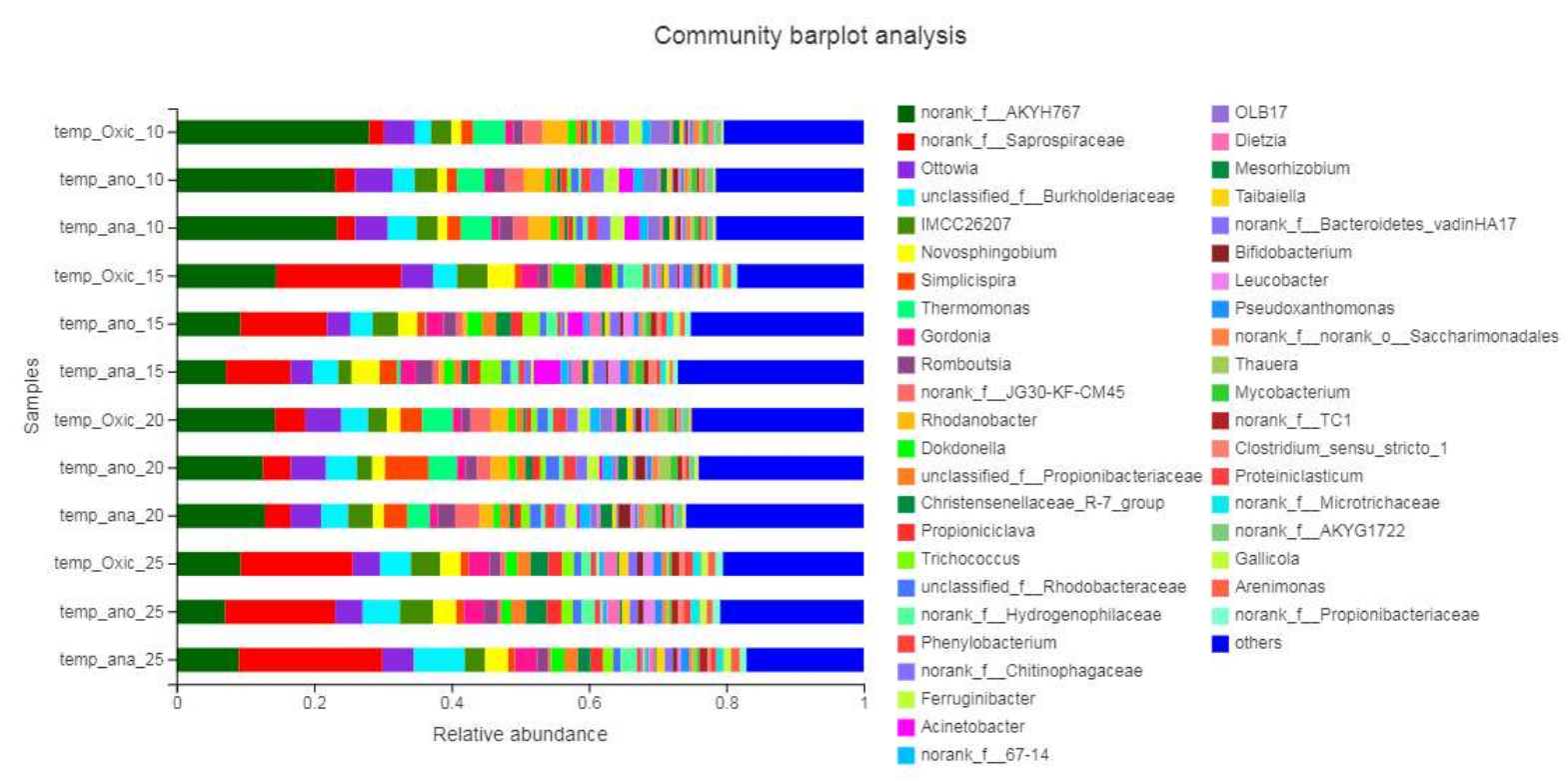

Figure 6. Community composition at the genus level.

Figure 6 shows that the common dominant bacterial genus were norank_f_AKYH767, norank_f_Saprospiraceae, Ottowia, unclassified_f_Burkholderiaceae, IMCC26207, Novosphingobium, Gordonia, Romboutsia octabacterium. A total of 719 Genus were obtained. The abundance of 8 Genus were 33.33-53.11\%, which represent the dominant genus in the plateau environment. The dominant bacteria at the genus level reported in previous studies (Yang et al. 2017, Chen et al. 2017) were relatively different, excluding Pseudomonas that were similar (Tian et al. 2015, Kang et al. 2019). The dominant bacterial community differed to these studies.

Thermomonas, Simplicispira, norank_f_JG30-KF-CM45, Rhodanobacter, Dokdonella, unclassified_f_Propionibacteriaceae, Christensenellaceae_R-7_group, Propioniciclava, Trichococcus, norank_f_Hydrogenophilaceae, unclassified_f__ Large (total abundance 15.3328.97\%) were more sensitive to temperature changes.
Norank_f_AKYH767, norank_f_Saprospiraceae,
Ferruginibacter, 
norank_f_Chitinophagaceae belong to the Bacteroidetes phylum, and these four genera of bacteria vary greatly under temperature conditions; Romboutsia, Christensenellaceae_R-7_group, Trichococcus belong to the Firmicutes phylum. Romboutsia did not significantly change between temperature and reactor. Christensenellaceae_R-7_group increased with increasing temperature, and the abundance of Trichococcus decreased with increasing temperature. Ottowia, unclassified_f_Burkholderiaceae, Novosphingobium, Thermomonas, Simplicispira, Rhodanobacter, Dokdonella, norank_f_Hydrogenophilaceae, unclassified_f__ Ottowia, unclassified_f_Burkholderiaceae, Simplicispira, norank_f_Hydrogenophilaceae belong to Betaproteobacteriales as phosphorus-accumulating bacteria. The corresponding proportion in the aerobic tank was significantly higher than other reactors. Norank_f_JG30-KF-CM45 belongs to the Chloroflexi door, which was greatly affected by the temperature conditions, the anoxic tank and the anaerobic tank.

The abundance of six common dominant genera of norank_f_AKYH767, norank_f_Saprospiraceae, Novosphingobium, Thermomonas, Simplicispira, and Gordonia significantly differed under different temperature conditions $(\mathrm{P} \leq 0.05)$. These included Norank_f_JG30- KF-CM45 (0.42-3.56\%), Rhodanobacter (0.03-4.70\%), Dokdonella (0.82$3.27 \%)$, unclassified_f_Propionibacteriaceae (0.79-2.11\%), Christensenellaceae_R-7_group
(0.25-3.01\%),
Propioniciclava
$(0.71-2.17 \%)$
Trichococcus
(0.47-3.04\%), norank_f_Hydrogenophilaceae (0.43-2.86\%), Phenylobacterium (0.52-1.93\%), Ferruginibacter (0.28-2.16\%), norank_f_Chitinophagaceae $(0.17-2.22 \%)$. There were significant differences at each temperature $(\mathrm{P} \leq 0.05)$. The abundance of the genus-level dominant Genus Romboutsia significantly differed between the reactors $(\mathrm{P} \leq 0.05)$. There were no significant differences between the other bacteria in the different reactors $(\mathrm{P}>0.05)$.

\subsubsection{Analysis of the characteristics of colony structure at the Species level}

Community barplot analysis
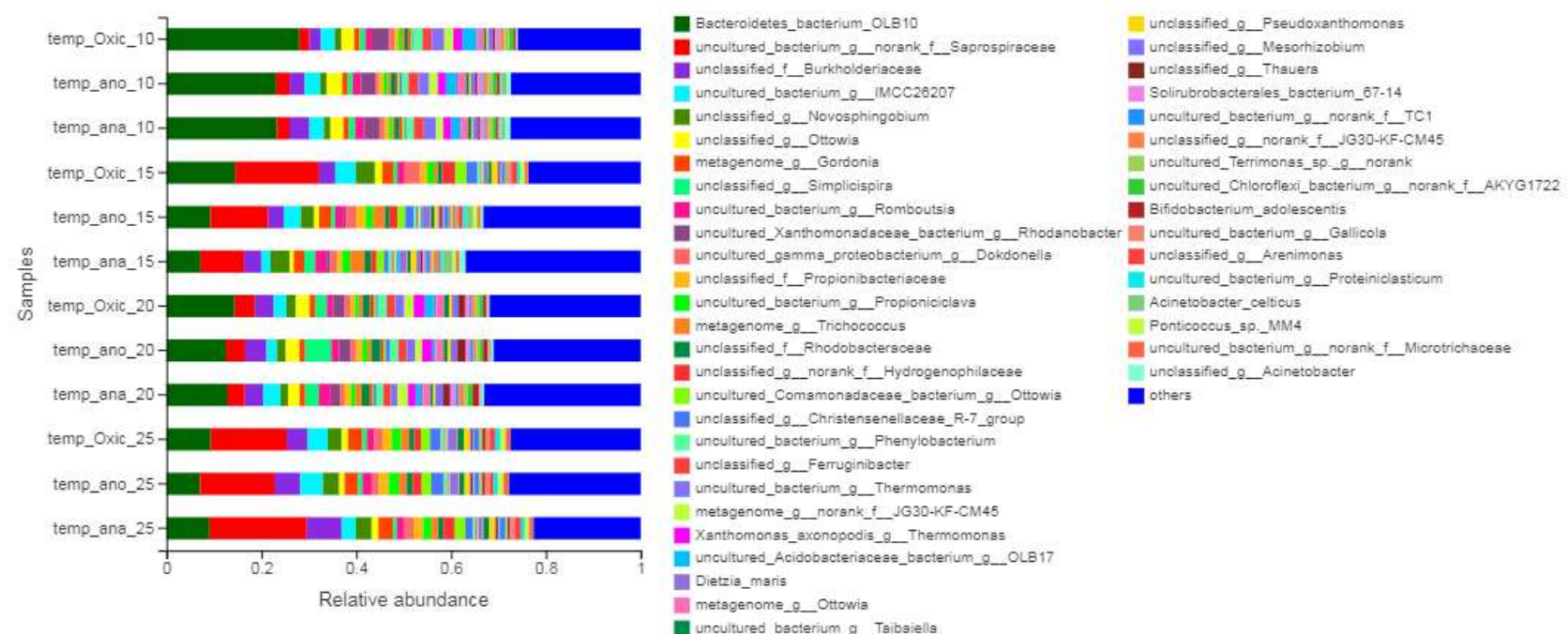

Figure 7. Community composition according to species.

From Figure 7, the common dominant bacteria genus under the above working conditions were Bacteroidetes_bacterium_OLB10, uncultured_bacterium_g_norank_f_Saprospiraceae, unclassified_f_Burkholderiaceae, uncultured_bacterium_g_IMCC26207, unclassified_g_Novosphingobium, metagenium_g_Gordordium, and bacteria. A total of 1178 
Species were obtained. The abundance of 8 Species were $28.11-47.98 \%$, which were the dominant strain in the plateau environment. Unclassified_g_Ottowia, unclassified_g_Simplicispira, uncultured_Xanthomonadaceae_bacterium_g_Rhodanobacter,

uncultured_gamma_proteobacterium_g__Dokdonella, unclassified_f_Propionibacteriaceae, uncultured_bacterium_g__Propioniciclava, unclassified_g_norank_f_Hydrogenophilaceae, metagenome_g_Trichococcus, uncultured_Comamonadaceae_bacterium_g_Ottowia, unclassified_g_Christensenellaceae_R7_group, uncultured_bacterium_g__Phenylobacterium, unclassified_g_Ferruginibacter, uncultured_bacterium_g_Thermomonas also showed changes in abundance. The metagenome_g_norank_f_JG30-KF-CM4515 Species were highly abundant (17.43-25.99\%) and more sensitive to temperature changes.

Uncultured_bacterium_g_IMCC26207, metagenome_g_Gordonia, unclassified_f_Propionibacteriaceae, uncultured_bacterium_g_Propioniciclava belong to the Actinobacteria phylum. The abundance of uncultured_bacterium_g_IMCC26207 increased as temperature increased. Unclassified_f_Propionibacteriaceae, uncultured_bacterium_g_Propioniciclava also increased at increasing temperature and were significantly superior to the other two reactors in the anoxic tank. Bacteroidetes_bacterium_OLB10, uncultured_bacterium_g_norank_f_Saprospiraceae_unknown_Bro_derobacterium_genotype_B _ Increased showed an upward trend and were most abundant in the aerobic tank. The abundance of unclassified_g_Ferruginibacter showed a downward trend at increasing temperatures. Uncultured_bacterium_g_Romboutsia, metagenome_g_trichococcus, unclassified_g_Christensenellaceae_R-7_group belong to Firmicutes_g, culture_rich_g-7 and decreased as temperature increased, at were highest in the anaerobic tank. The abundance of unclassified_g_Christensenellaceae_R-7_group_increased with temperature. Unclassified_f_Burkholderiaceae, unclassified_g_Novosphingobium, unclassified_g_Ottowia, unclassified_g_Simplicispira, uncultured_Xanthomonadaceae_bacterium_g_Rhodanobacter, uncultured_gamma_proteobacterium_g__Dokdonella,

unclassified_g_norank_f_Hydrogenophilaceae,_unclassified_f_Rhodobacteraceae, uncultured_Comamonadaceae_bacterium_g_Ottowia,

uncultured_bacterium_g_Phenylobacterium, uncultured_bacterium_g_Thermomonas belongs Proteobacteria door, wherein unclassified_f_Burkholderiaceae, unclassified_g_Ottowia, unclassified_g__Simplicispira, unclassified_g_norank_f_Hydrogenophilaceae, uncultured_Comamonadaceae_bacterium_g_Ottowia belonging to Betaproteobacteriales of PAOs; metagenome_g_norank_f_JG30-KF-CM45, unclassified_g_norank_f_JG30-KF-CM45, uncultured_Chloroflexi_bacterium_g_norank_f_AKYG1722,

metagenome_g_norank_f_JG30-KF-CM45 belong to Chloroflexi door and showed fluctuations at different temperatures.

Bacteroidetes_bacterium_OLB10, uncultured_bacterium_g_norank_f_Saprospiraceae, unclassified_g_Novosphingobium, unclassified_g_Ottowia, metagenome_g_Gordonia showed significant changes in abundance (5.52\%), uncultured_Xanthomonadaceae_bacterium_g_Rhodanobacter $\quad(0.03-3.62 \%)$, uncultured_gamma_proteobacterium_g__Dokdonella unclassified_f_Propionibacteriaceae (0.79-2.11\%), uncultured_bacterium_g_Propioniciclava (0.70-2.14\%), unclassified_g_norank_f_Hydrogenophilaceae (0.43-2.86\%), 
uncultured_Comamonadaceae_bacterium_g_Ottowia

$(0.36-2.32 \%)$

unclassified_g_Christensenellaceae_R-7_group

$(0.22-2.68 \%)$,

uncultured_bacterium_g_Phenylobacterium

$(0.51-1.92 \%)$,

uncultured_bacterium_g_Thermomonas $(0.00-2.67 \%)$, metagenome_g_norank_f_JG30-KFCM45 (0.17-2.25\%). These data suggest that temperature has a significant effect on all these bacteria. The abundance of the dominant bacteria uncultured_bacterium_g_Romboutsia at the species level significantly differed between the reactors $(\mathrm{P} \leq 0.05)$. There were no significant difference between other dominant bacteria in different reactors $(\mathrm{P}>0.05)$.

\subsection{Relationship between colony structure of the sewage treatment system and environmental} factors

Correlation analysis of the environmental factors and colony structure were performed through RDA/CCA analysis, which carries out regression analysis on the community structure and environmental factors at different temperature to reflect the relationship between the community structure and environmental factors. The microbial classification level is Species, environment. The factors corresponding to temperature, $\mathrm{TN}, \mathrm{TP}, \mathrm{NH}_{3}-\mathrm{N}$ and $\mathrm{COD}$ were assessed. Given the purpose of the experiment design, CCA analysis was performed for the anaerobic tank, anoxic tank and aerobic tank.

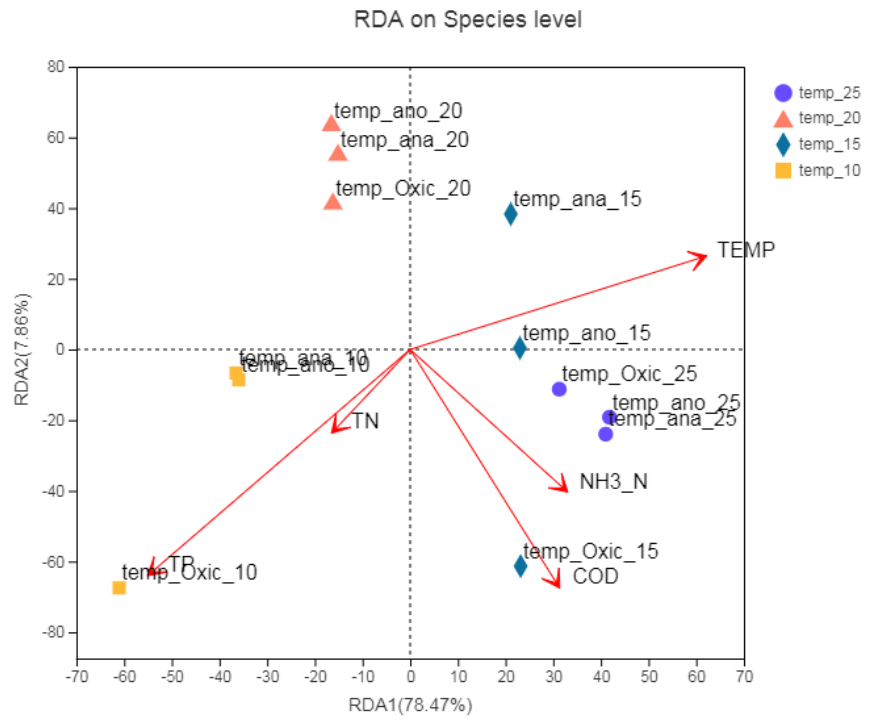

Figure 8. CCA analysis.

CCA analysis showed that the correlation coefficients $r$ of temperature, $\mathrm{TN}, \mathrm{TP}, \mathrm{NH}_{3}-\mathrm{N}$, and COD were $0.9555,-0.7292,-0.7916,0.77882$, and 0.5565 , respectively. Significance analysis showed that the correlation between temperature and the samples was significant $(p<0.05)$, suggesting that environmental factors show a significant relationship to sample colony structure. The removal rate of $\mathrm{TP}, \mathrm{TN}, \mathrm{NH}_{3}-\mathrm{N}$, and $\mathrm{COD}$ were affected by the sample community structure. The degree of impact was sequentially weakened. The interpretation degree of RDA1 and RDA2 were $78.47 \%$ and $7.86 \%$ respectively.

We used correlation Heatmaps to analyze the relationship between different species and environmental variables. To assess the correlation between microorganisms and environmental variables (temperature, $\mathrm{TN}, \mathrm{TP}, \mathrm{NH}_{3}-\mathrm{N}$, and $\mathrm{COD}$ ) samples were classified according to the top 50 species. 


\section{Spearman Correlation Heatmap}

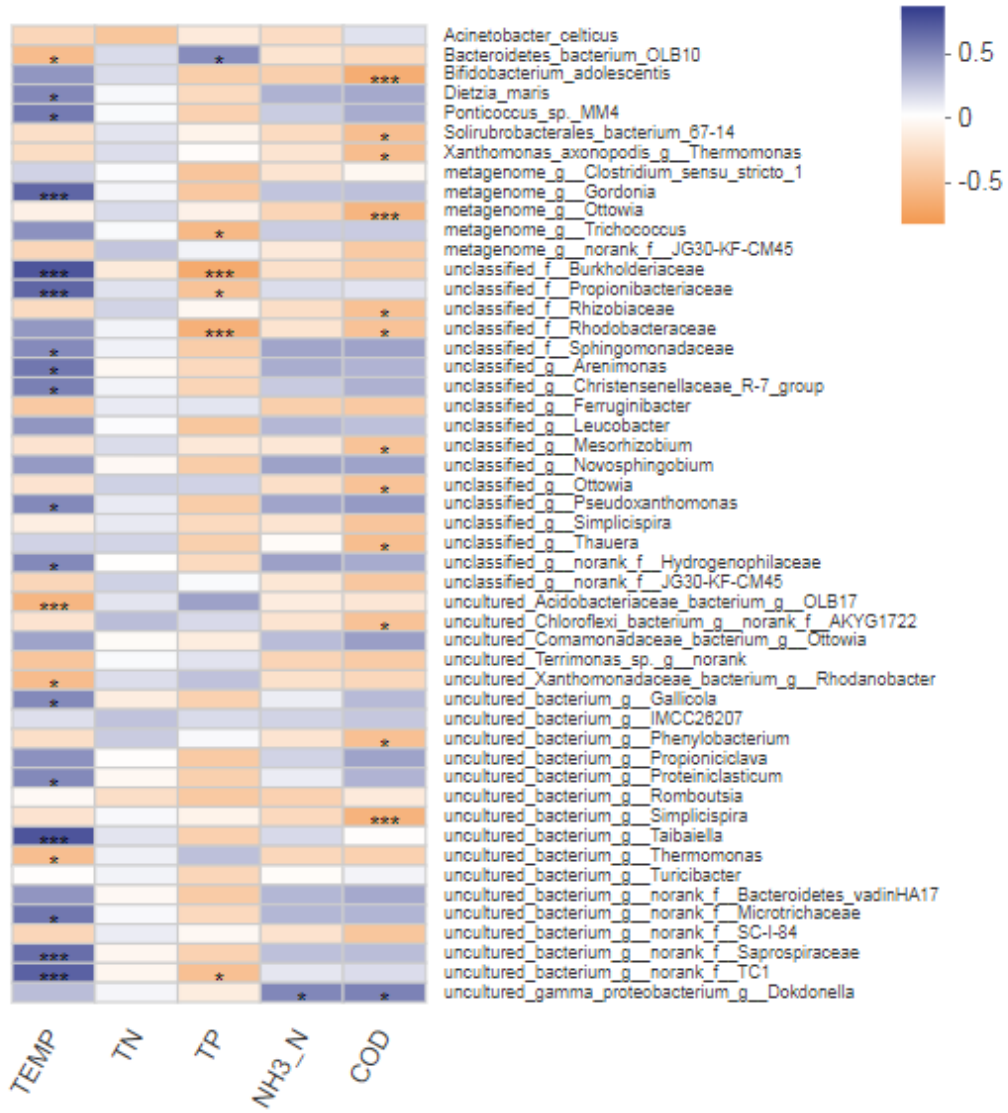

Figure 9. Correlation Heatmap.

Figure 9 shows that: 1) at the species level, temperature is significantly related to the species

Bacteroidetes_bacterium_OLB10,

unclassified_f_Sphingomonadaceae,

unclassified g Christensenellaceae R-7 group,

unclassified_g_norank_f_Hydrogenophilaceae,

uncultured_Xanthomonadaceae_bacterium_g_Rhodanobacter,

uncultured_bacterium_g_Gallicola, uncultured_bacterium_g_Proteiniclasticum, uncultured_bacterium_g_tThermomonas, uncultured_bacterium_g_norank_f_Microtrichaceae. Temperature also significantly influenced related species including metagenome_g_Gordonia, unclassified_f_Burkholderiaceae, unclassified_f_Propionibacteriaceae, uncultured_Acidobacteriaceae_bacterium_g_OLB17, uncultured_bacterium_g_Taibaiella, uncultured_bacterium_g_norank_f_Saprospiraceae, and uncultured_bacterium_g_norank_f_TC1. TN correlated to the absence of certain bacterial species. TP was significantly associated with species of Bacteroidetes_bacterium_OLB10, metagenome_g_Trichococcus, unclassified_f_Propionibacteriaceae, uncultured_bacterium_g_norank_f_TC1. TP was significantly related to unclassified_f_Burkholderiaceae, unclassified_f_Rhodobacteracea E. $\mathrm{NH}_{3}-\mathrm{N}$ was significantly related to uncultured_gamma_proteobacterium_g_Dokdonella. COD was significantly associated with Solirubrobacterales_bacterium_67-14, Xanthomonas_axonopodis_g_Thermomonas, unclassified_f_Rhizobiaceae, 
unclassified_g_Mesorhizobium, unclassified_g_Ottowia, unclassified_g_thauera, uncultured_Chloroflexi_bacterium_g_norank_f_AKYG1722,

uncultured_bacterium_g_Phenylobacterium,

uncultured_gamma_proteobacterium_g_Dokdonella. Extremely relevant bacteria and COD

species included Bifidobacterium_adolescentis, metagenome_g_Ottowia, and uncultured_bacterium_g__Simplicispira.

\section{Conclusions}

Using 16SrRNA gene sequencing and correlation analysis, the differences in bacterial communities in anaerobic, anoxic and aerobic tanks under four temperature conditions were analyzed based on species number, diversity, composition, and Heatmaps of the sequenced samples.

1) Sequencing analysis revealed that the number of species in the phylum, Class, order, family, genus and species level in the high-in situ samples were lower than those previously reported and varied according to the working conditions of the three reactors. There were significant differences in community number at the phylum, class, order, family, genus and species level. A significant correlation was observed between the number of community at the phylum, Class, order, family, genus and species level $(\mathrm{P} \leq 0.05)$. However, no obvious correlation between temperature and the number of phylum, class, order, family, genus and species of each tank were observed.

2) Alpha diversity analysis showed that the community richness, community uniformity, and community diversity under high in situ temperatures differed to those reported in the literature. $\mathrm{T}$ tests showed that, excluding $10^{\circ} \mathrm{C}$ and $20^{\circ} \mathrm{C}$, significant differences exist in the number of community according to working conditions. Community diversity coefficients were also significantly different between $10{ }^{\circ} \mathrm{C}$ and $20{ }^{\circ} \mathrm{C}, 10{ }^{\circ} \mathrm{C}$ and $15{ }^{\circ} \mathrm{C}$, and $20{ }^{\circ} \mathrm{C}$ and $25{ }^{\circ} \mathrm{C}$. The community richness chao coefficient was significantly different between the three groups of operating conditions at $10^{\circ} \mathrm{C}$ and $15^{\circ} \mathrm{C}, 20^{\circ} \mathrm{C}$ and $25^{\circ} \mathrm{C}$, and $15^{\circ} \mathrm{C}$ and $25^{\circ} \mathrm{C}$. The Simpsoneven coefficient of community uniformity showed that at $10^{\circ} \mathrm{C}$, there were significant differences between the three groups of operating conditions at $20^{\circ} \mathrm{C}, 10^{\circ} \mathrm{C}$ and $20^{\circ} \mathrm{C}, 20^{\circ} \mathrm{C}$ and $25^{\circ} \mathrm{C}$. Significance analysis of the three reactors showed no significant differences in the community numbers in the different reactors.

3) We assessed the community composition of the three reactors under different temperature conditions according to Phylum, Class, Order, Family, Genus, and species. The common dominant community at each level were analyzed and their response to temperature were assessed.

4) Using the CCA chart to further verify that temperature is an important factor that influences the composition of the colony structure, and using the correlation heatmap to analyze the species that are significantly related to temperature, our analysis showed that the abundance of 13 species were related to temperature. In total, 7 species showed a significant correlation; TN significantly correlated were not observed; 4 species correlated with TP, 2 of which showed a high correlation; 1 species significantly correlated with $\mathrm{NH}_{3}-\mathrm{N}$; a single species significantly correlated with COD.

Based on these analysis, the $\mathrm{A} 2 \mathrm{O}$ species structure in high-in situ correlated with temperature in terms of species number, Alpha diversity, and dominant species composition. The dominant bacteria that were significantly related to temperature at the species level were Bacteroidetes_bacterium_OLB10. The dominant bacteria with an extremely significant correlation were metagenome_g_Gordonia, unclassified_f_Burkholderiaceae, uncultured_bacterium_g_norank_f_Saprospiraceae. The dominant bacteria with significant TP removal rates were Bacteroidetes_bacterium_OLB10. The dominant bacteria with extremely 
significant TP removal rates were unclassified_fae. bacteria.

\section{Declarations}

\section{Ethics approval and consent to participate}

Not applicable.

\section{Consent for publication}

Written informed consent for publication was obtained from all participants..

\section{Availability of data and materials}

Due to the confidentiality of the experimental data and the experimental research is in the basic mechanism research stage, the experimental data will not be disclosed for the time being. The data set generated and/or analyzed during the current research period cannot be publicly obtained, but can be obtained from the corresponding author according to reasonable requirements Obtained there. The data in this article can be used after obtaining the consent of all authors. The email address for obtaining data: 1916619203@qq.com.

\section{Competing interests}

The authors declare that they have no competing interests.

\section{Funding}

The study was supported by the National Natural Science Foundation of China (NO. 51868069, 51769034), Natural Science Foundation of Tibet (NO. XZ 2018 ZR G-20), the Program for Scientific Research Innovation Team in Colleges and Universities of Tibet Autonomous Region.

\section{Authors' contributions}

ZONG Yongchen and LU Guanghua conceived and designed this study. LI Yuanwei, HUANG Decai and HAO Kaiyue conducted experiments. ZONG Yongchen analyzed the data and wrote the manuscript. All authors reviewed the manuscript. The authors read and approved the final manuscript.

\section{Acknowledgements}

Not applicable.

Authors' information ${ }^{1}$ Res. Institute of Tibet Plateau Ecology, Tibet Agriculture \& Animal Husbandry University, Linzhi 860000,China. ${ }^{2}$ Tibet Key Laboratory of Forest Ecology in Plateau Area, Ministry of Education, Linzhi 860000,China. ${ }^{3}$ National Key Station of Field Scientific Observation \& Experiment, Linzhi 860000,China. ${ }^{4}$ Key Laboratory of Forest Ecology in Plateau Area, Tibet Autonomous Region, Linzhi 860000,China. ${ }^{5}$ United Key Laboratories of Ecological Security, Tibet Autonomous Region, Linzhi 860000,China. ${ }^{6}$ Water Conservancy Project \& Civil Engineering College, Tibet Agriculture \& Animal Husbandry University, Linzhi 860000,China Zong Yongchen email: 35099371@qq.com

LI Yuanwei email:1916619203@qq.com

HUANG Decai email: 965455430@qq.com 
HAO Kaiyue email: 2388155202@qq.com

LU Guanghua email: 3588416157@qq.com

Institution address: Tibet Agriculture \& Animal Husbandry University, No. 100 Yucai West Road, Bayi District,

Linzhi City, Tibet Autonomous Region, China

\section{References}

1. Zong, Y. C., Hao, K. Y., Li, Y. W., Lu, G. H., \& Huang, D. C. (2019). NITROGEN AND PHOSPHOROUS REMOVAL OF PILOT-SCALE ANAEROBIC-ANOXIC-AEROBIC PROCESS UNDER PLATEAU ENVIRONMENTAL FACTORS. APPLIED ECOLOGY AND ENVIRONMENTAL RESEARCH , 17 (5), 12213-12226. https://doi.org/10.15666/aeer/1705 1221312226

2. Zhai, J., Chen, M., Xiao, H., \& Chen, Z. (2012). Solar preheating/biological contact oxidation/compound constructed wetland for treatment of sewage from tibet plateau area. China Water \& Wastewater, 28(2), 42-45. https://doi.org/10.1007/s11783-011-0280-z

3. Chen, X., HAO K., SU, D., \& ZONG, Y.(2018).Characteristic Study on Wastewater Treatment in High Altitude Area by A2/O Process. China Technology of Water Treatment, 44(02),93-96. https://doi.org/10.16796/j.cnki.1000-3770.2018.02.022

4. Zong, Y., Li, Y., Hao, K., Lu, G., \& Huang, D. (2019). INFLUENCE OF TRANSIENT CHANGE OF WATER TEMPERATURE ON PILOT-SCALE ANAEROBIC-ANOXICOXIC PROCESS UNDER PLATEAU ENVIRONMENTAL FACTORS. APPLIED ECOLOGY AND ENVIRONMENTAL RESEARCH , 17 (5), 12191-12202. https://doi.org/10.15666/aeer/1705_1219112202

5. Tian, M., Zhao, F., Shen, X. , Chu, K. , Wang, J. , \& Chen, S. (2015). The first metagenome of activated sludge from full-scale anaerobic/anoxic/oxic(a2o) nitrogen and phosphorus removal reactor using illumina sequencing. Journal of Environmental Sciences, 35:181-190. https://doi.org/10.1016/j.jes.2014.12.027

6. Nasha, D. , \& Lin, W. . (2016). Microbial community structure and the performance of biological aerated filter under different temperatures. chinese journal of environmental engineering. https://doi.org/ 10.12030/j.cjee.201501153

7. Fang, Z ., SUN, P ., ZHONG, X., \&JIANG T. (2011). Effect of water temperature on the microbial community in an enhanced biological phosphorus removal system. acta scientiae circumstantiae, 31(5), 941-947. https://doi.org/10.13671/j.hjkxxb.2011.05.015

8. Ma, X., Zhao, B., Zhang, X., Xie, F., Cui, Y., Li, H., \& Yue, X. (2020). Effect of periodic temperature shock on nitrogen removal performance and microbial community structure in plug-flow microaerobic sludge blanket. Chemosphere, 241, 124934. https://doi.org/10.1016/j.chemosphere.2019.124934

9. Liao, K, Hu, H, Ma,S., \&Ren, H.. (2019). Effect of microbial activity and microbial community structure on the formation of dissolved organic nitrogen (DON) and bioavailable DON driven by low temperatures.[J]. Water research, 159. https://doi.org/10.1016/j.watres.2019.04.049

10. Chen, Y., Lan. S., Wang, L., Dong, S., Zhou, H., Tan, Z., Li, X..[2017] A review: Driving factors and regulation strategies of microbial community structure and dynamics in wastewater treatment systems.[J]. Chemosphere, 174. https://doi.org/10.1016/j.chemosphere.2017.01.129

11. Paul G. McAteer,Anna Christine Trego,Camilla Thorn,Therese Mahony,Florence Abram,Vincent O'Flaherty. (2020). Reactor configuration influences microbial community structure during high-rate, low-temperature anaerobic treatment of dairy wastewater[J]. Bioresource Technology, 307. https://doi.org/10.1016/j.biortech.2020.123221

12. Simon, S. D. , \& Lesage, J. P. . (1989). Assessing the accuracy of anova calculations in statistical software. Computational Statistics \& Data Analysis, 8(3), 325-332. https://doi.org/10.1016/0167-9473(89)90048-0

13. Sun, F. L., Fan, L. L., Wang, Y. S., \& Huang, L. Y. (2019). Metagenomic analysis of the inhibitory effect of chromium on microbial communities and removal efficiency in A2O sludge. Journal of hazardous materials, 368, 523-529.

https://doi.org/10.1016/j.jhazmat.2019.01.076 
14. Wen, Y., Wang, X., Lin, C.(2015):Bacterial community dynamics in an activated sludge system based on Miseq sequencingMiseq. Chinese Journal of Environmental Engineering,9(11),5225-5230. http://kns.cnki.net/kcms/detail/detail.aspx?FileName=HJJZ201511016\&DbName=CJFQ2015

15. Jin X, Zhao Z, Qin Z, et al. (2017): Distribution and degradation of organic matter with different molecular weight in an A 2/O treatment system[J]. Applied Water Science, 7(7): 3497-3502. https://doi.org/10.1007/s13201-017-0616-3

16. ZHANG Xiao-Hong, JIANG Bo, ZHANG Wen-Wu, CHEN Li-Ming, GUO Hong-Li. (2019): Microbial community diversity of activated sludge from municipal wastewater treatment plants in Beijing-Tianjin-Hebei region[J]. Microbiology China, 46(8): 1896-1906. https://doi.org/10.13344/j.microbiol.china.190366

17. Fan, X. Y., Gao, J. F., Pan, K. L., Li, D. C., Dai, H. H., \& Li, X. (2018):Functional genera, potential pathogens and predicted antibiotic resistance genes in 16 full-scale wastewater treatment plants treating different types of wastewater. Bioresource technology, 268, 97-106. https://doi.org/10.1016/j.biortech.2018.07.118

18. WANG,X.,GAO,M.,WANG,Y.,YANG,Y.,GANG, J.,FU, G.,WANG,L.(2019): Effect of Online $\mathrm{Na} \mathrm{Cl} \mathrm{O}$ Backwashing on Microbial Communities in an Inverted A2O-MBR System, Chinese Journal of Environmental Science,40(7),3208-3215. https://doi.org/10.13227/j.hjkx.201811254

19. Zhang, L., Zhang, M., Guo, J., Zheng, J., Chen, Z., \& Zhang, H. (2019):Effects of K+ salinity on the sludge activity and the microbial community structure of an $\mathrm{A} 2 \mathrm{O}$ process. Chemosphere, 235, 805-813. https://doi.org/10.1016/j.chemosphere.2019.06.137

20. LI, G., SONG,J., LI, X., ZHANG, S., TAO, L., ZHANG, C.(2014) :Metabolic Characteristics and Functional Diversity of Carbon Source in Microflora of Ponds with Recirculating Aquaculture System. Agricultural Science \& Technology. 15(2): 278-282, 299. https://doi.org/10.3969/j.issn.1009-4229.2014.02.026

21. Chen, C., Ouyang, W., Huang, S., \& Peng, X. (2018):Microbial community composition in a simultaneous nitrification and denitrification bioreactor for domestic wastewater treatment. In IOP Conference Series: Earth and Environmental Science (Vol. 112, No. 1, p. 012007). IOP Publishing. https://doi.org/10.1088/1755-1315/112/1/012007

22. Cydzik-Kwiatkowska, A., \& Zielińska, M. (2016):Bacterial communities in full-scale wastewater treatment systems. World Journal of Microbiology and Biotechnology, 32(4), 66. https://ink.springer.com/article/10.1007/s11274-016-2012-9

23. Muszyński, A., Tabernacka, A., \& Miłobędzka, A. (2015):Long-term dynamics of the microbial community in a full-scale wastewater treatment plant. International biodeterioration \& biodegradation, 100, 44-51 https://doi.org/10.1016/j.ibiod.2015.02.008

24. Kang, A. J., Munz, G., \& Yuan, Q. (2019):Influence of pH control on material characteristics, bacterial community composition and BNR performance of mature aerobic granules. Process Safety and Environmental Protection, 124, 158-166. https://doi.org/10.1016/j.psep.2019.02.014

25. Juretschko, S., Loy, A., Lehner, A., \& Wagner, M. (2002):The microbial community composition of a nitrifying-denitrifying activated sludge from an industrial sewage treatment plant analyzed by the full-cycle rRNA approach. Systematic and applied microbiology, 25(1), 84. https://doi.org/10.1078/0723-2020-00093

26. Kong, Y., Xia, Y., Nielsen, J. L., \& Nielsen, P. H. (2007):Structure and function of the microbial community in a full-scale enhanced biological phosphorus removal plant. Microbiology, 153(12), 4061-4073. https://doi.org/10.1099/mic.0.2007/007245-0

27. Beer, M., Stratton, H. M., Griffiths, P. C., \& Seviour, R. J. (2010):Which are the polyphosphate accumulating organisms in full - scale activated sludge enhanced biological phosphate removal systems in Australia?. Journal of applied microbiology, 100(2), 233-243. https://doi.org/10.1111/j.1365-2672.2005.02784.x

28. Wong, M. T., Mino, T., Seviour, R. J., Onuki, M., \& Liu, W. T. (2005):In situ identification and characterization of the microbial community structure of full-scale enhanced biological phosphorous removal plants in Japan. Water Research, 39(13), 2901-2914. https://doi.org/10.1016/j.watres.2005.05.015

29. Nielsen, P. H., Saunders, A. M., Hansen, A. A., Larsen, P., \& Nielsen, J. L. (2012):Microbial communities involved in enhanced biological phosphorus removal from wastewater-a model 
system in environmental biotechnology. Current opinion in biotechnology, 23(3), 452-459. https://doi.org/10.1016/j.copbio.2011.11.027

30. Schmid, M., Thill, A., Purkhold, U., Walcher, M., Bottero, J. Y., Ginestet, P., ... \& Wagner, M. (2003):Characterization of activated sludge flocs by confocal laser scanning microscopy and image analysis. Water research, 37(9), 2043-2052. https://doi.org/10.1016/S00431354(02)00616-4

31. Zhang, B., Xu, X., \& Zhu, L. (2018). Activated sludge bacterial communities of typical wastewater treatment plants: distinct genera identification and metabolic potential differential analysis. AMB Express, 8(1), 184. https://doi.org/10.1186/s13568-018-0714-0

32. Chen, H., \& Chang, S. (2017). Impact of temperatures on microbial community structures of $s$ ewage sludge biological hydrolysis. Bioresource technology, 245, 502-510. https://doi.org/10.1016/j.biortech.2017.08.143

33. Yang, Q., Zhao, H., \& Du, B. (2017):Bacteria and bacteriophage communities in bulking and non-bulking activated sludge in full-scale municipal wastewater treatment systems. Biochemical Engineering Journal, 119, 101-111. https://doi.org/10.1016/j.bej.2016.12.017 
Figures

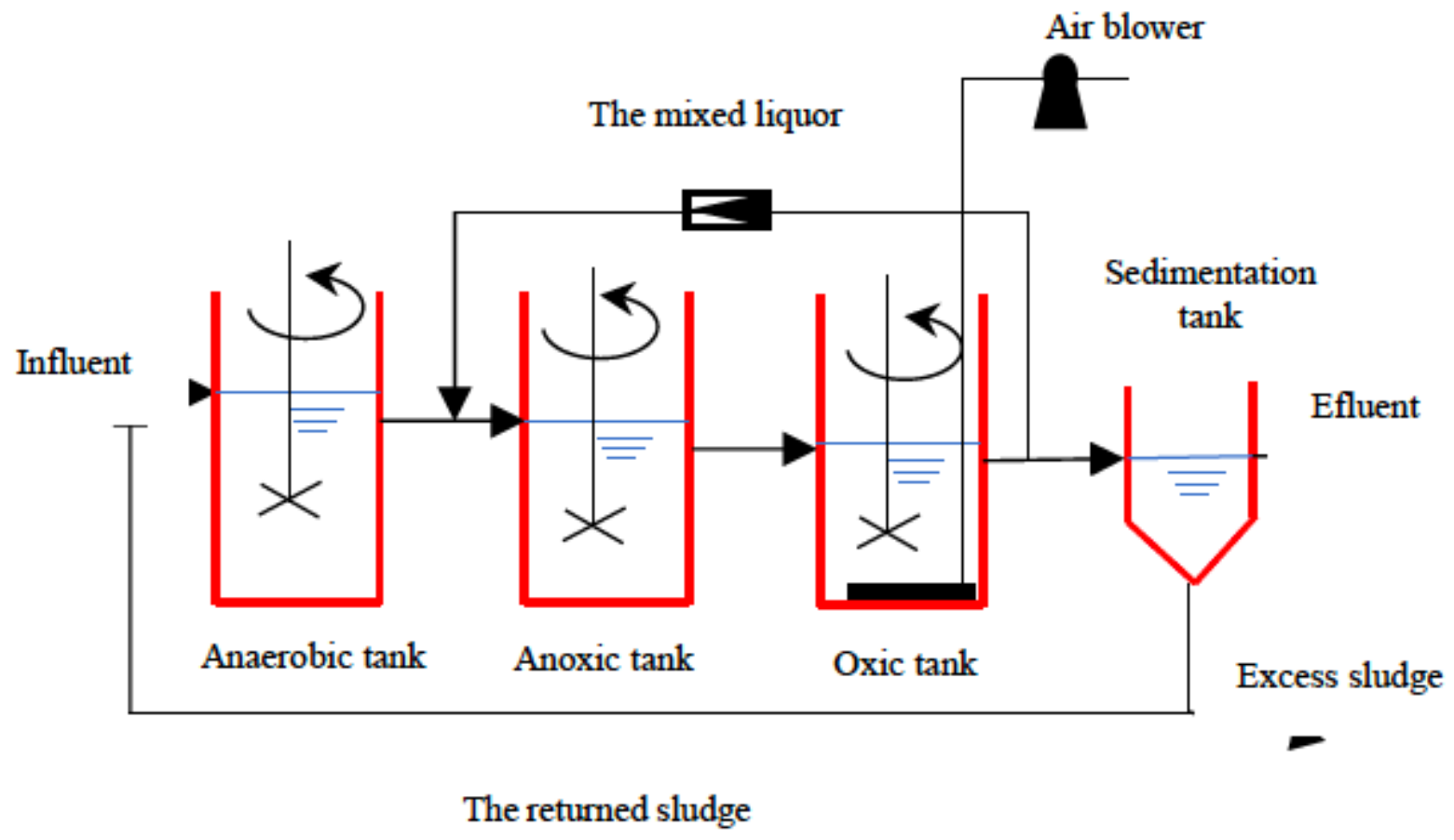

Figure 1

Schematic of Anaerobic-Anoxic-Oxic process

Community barplot analysis

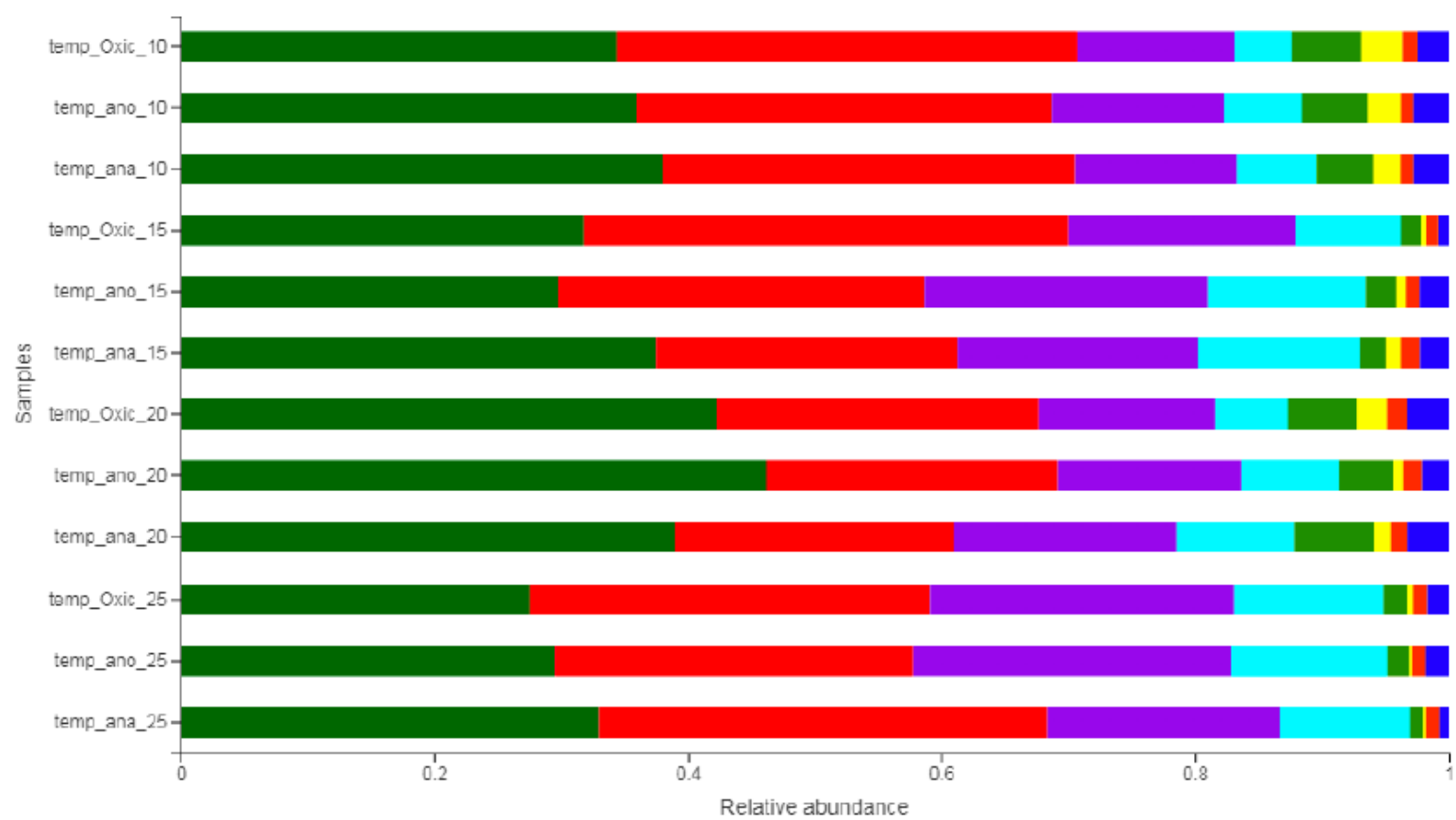

- Proteooacterla

Bacteroidetes

Actinobacteria

Firmicutes

Chlorofloxi

Acidobacteria

- Patescibacteria

others

Relative abundance 
Figure 2

Community composition according to Phylum level

Community barplot analysis

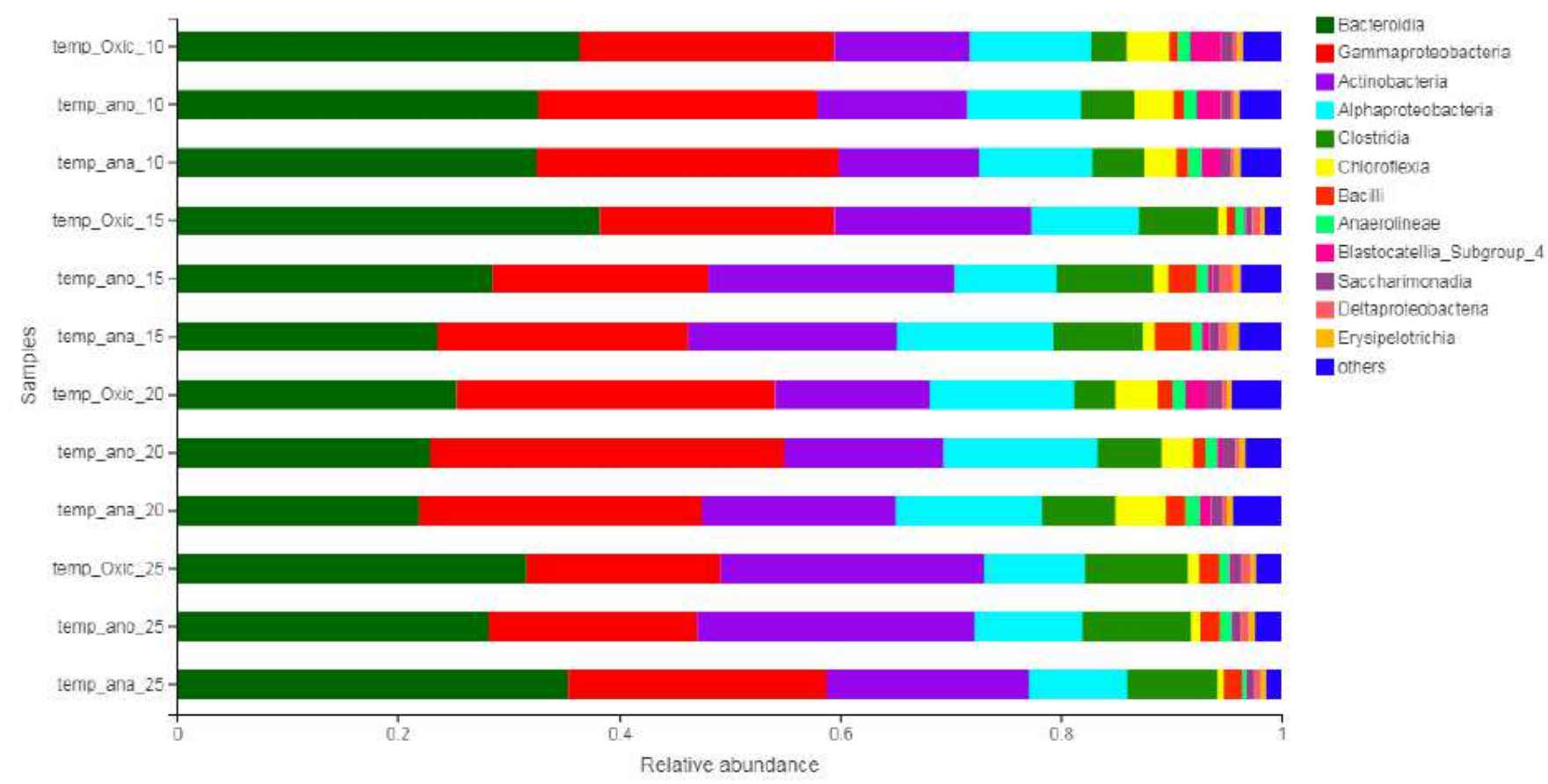

Figure 3

Community composition according to Class level. 


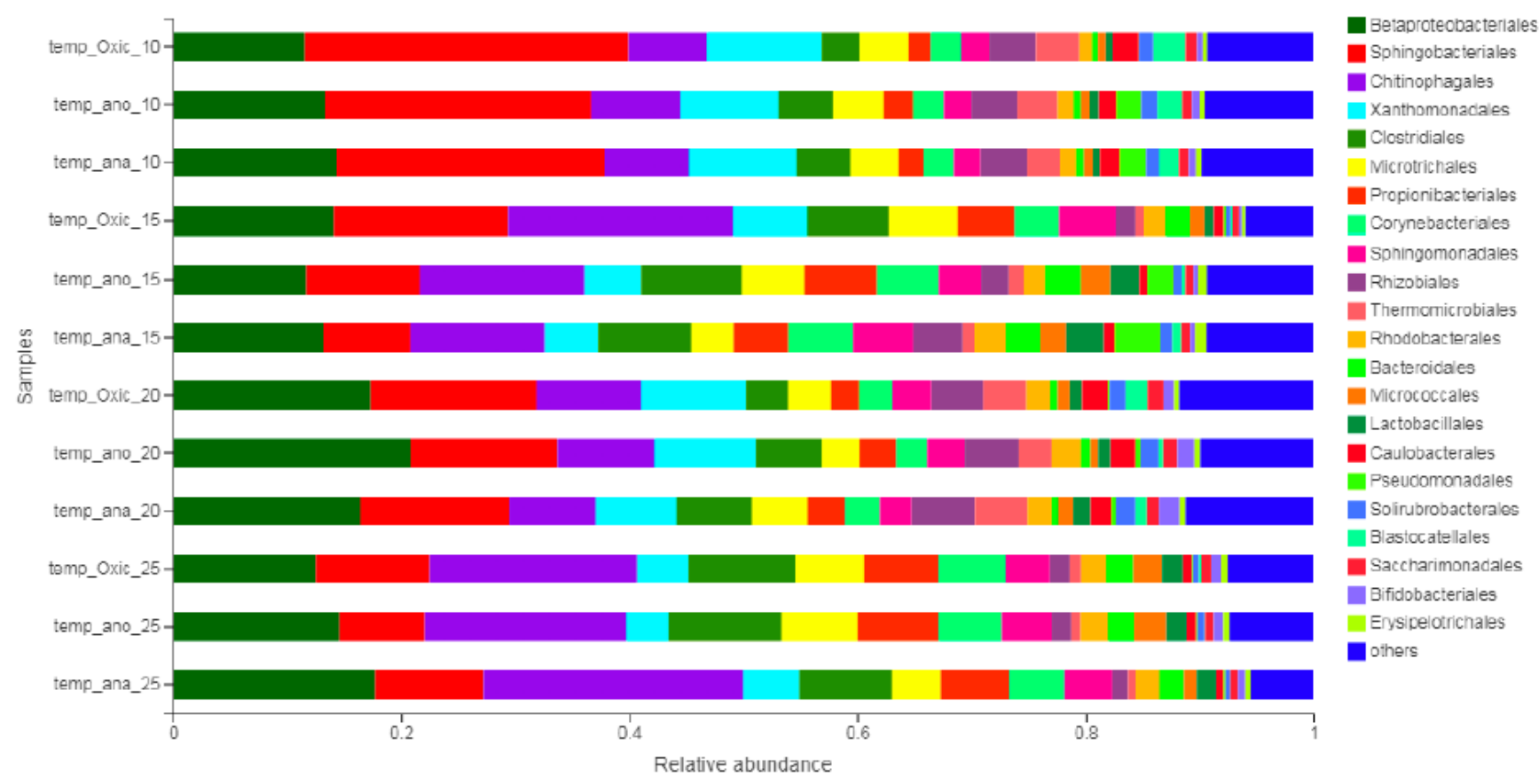

Figure 4

Community composition according to order.

Community barplot analysis

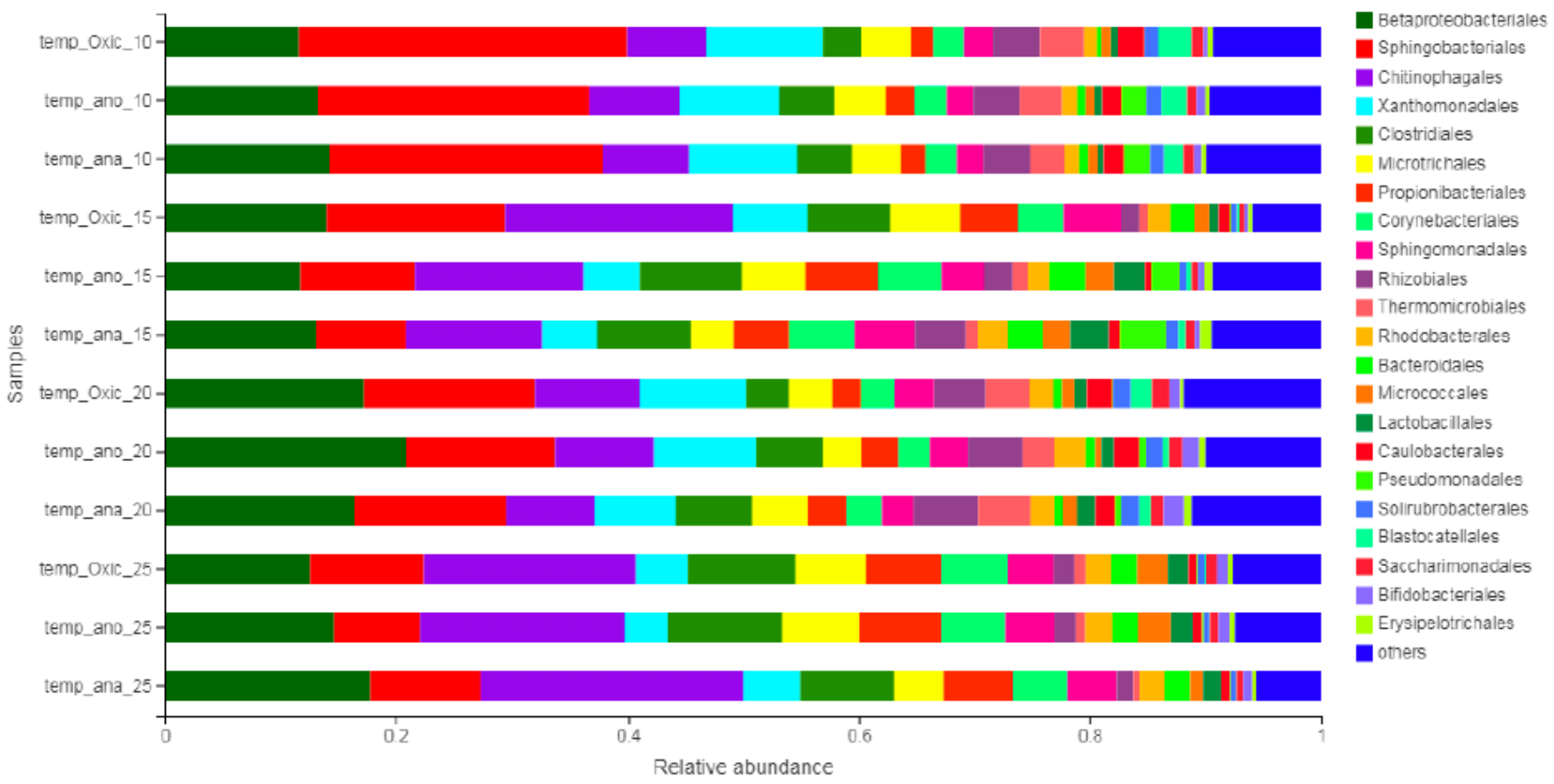

Figure 5 
Community composition according to family level.

Community barplot analysis

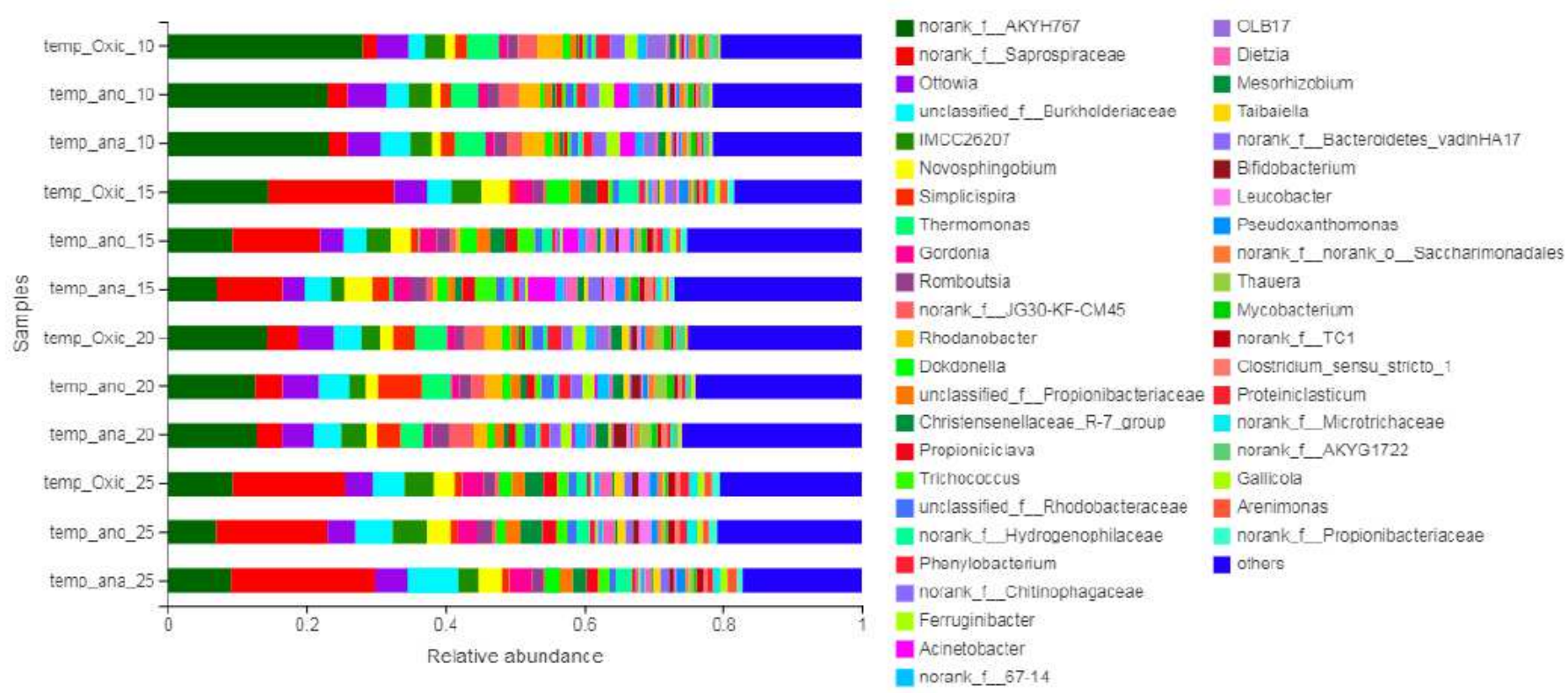

Figure 6

Community composition at the genus level.

Community barplot analysis
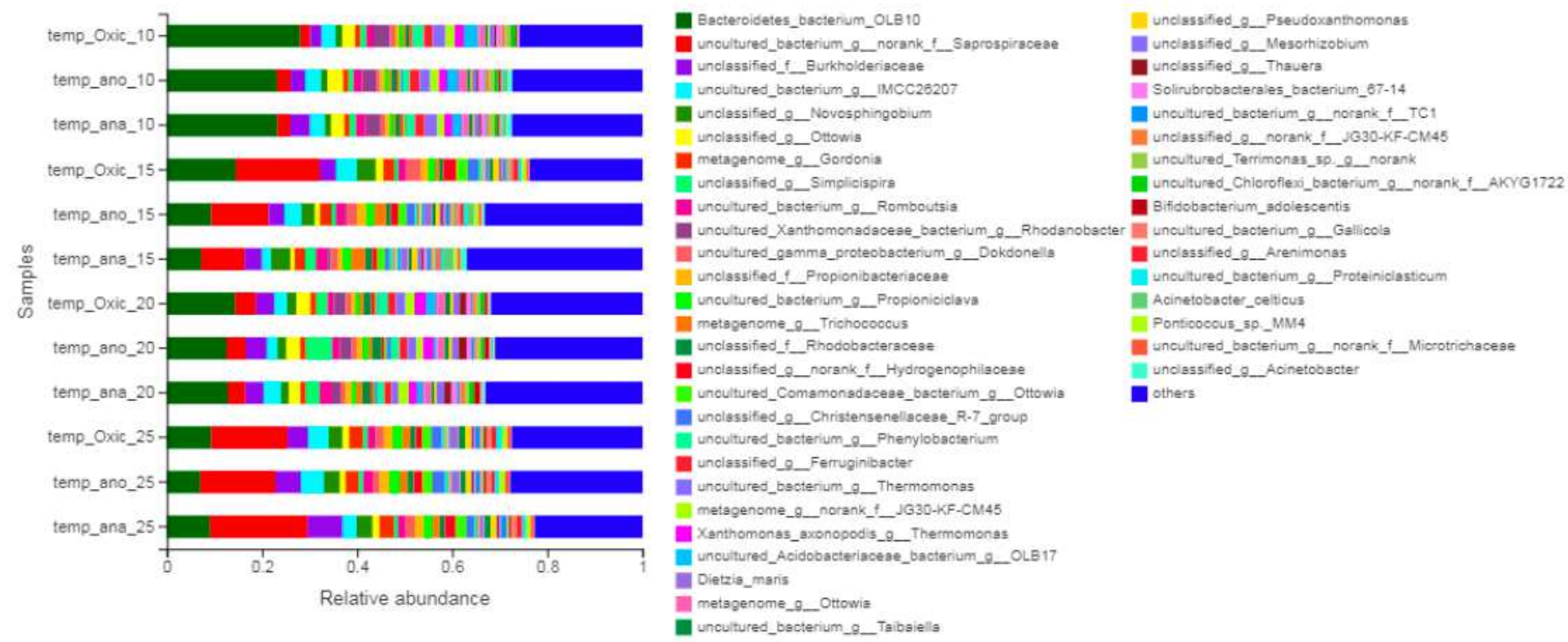

Figure 7

Community composition according to species. 
RDA on Species level

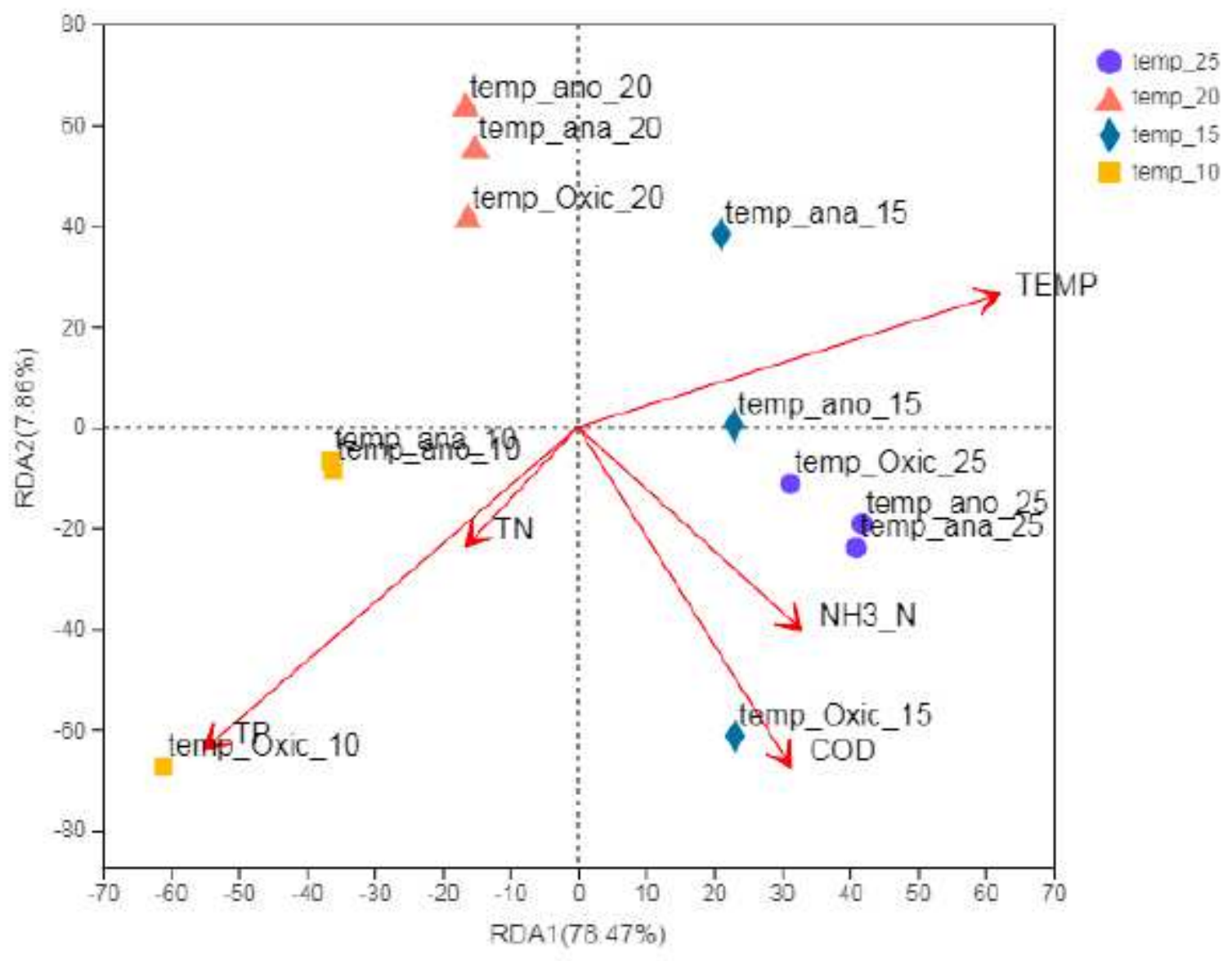

Figure 8

CCA analysis. 


\section{Spearman Correlation Heatmap}

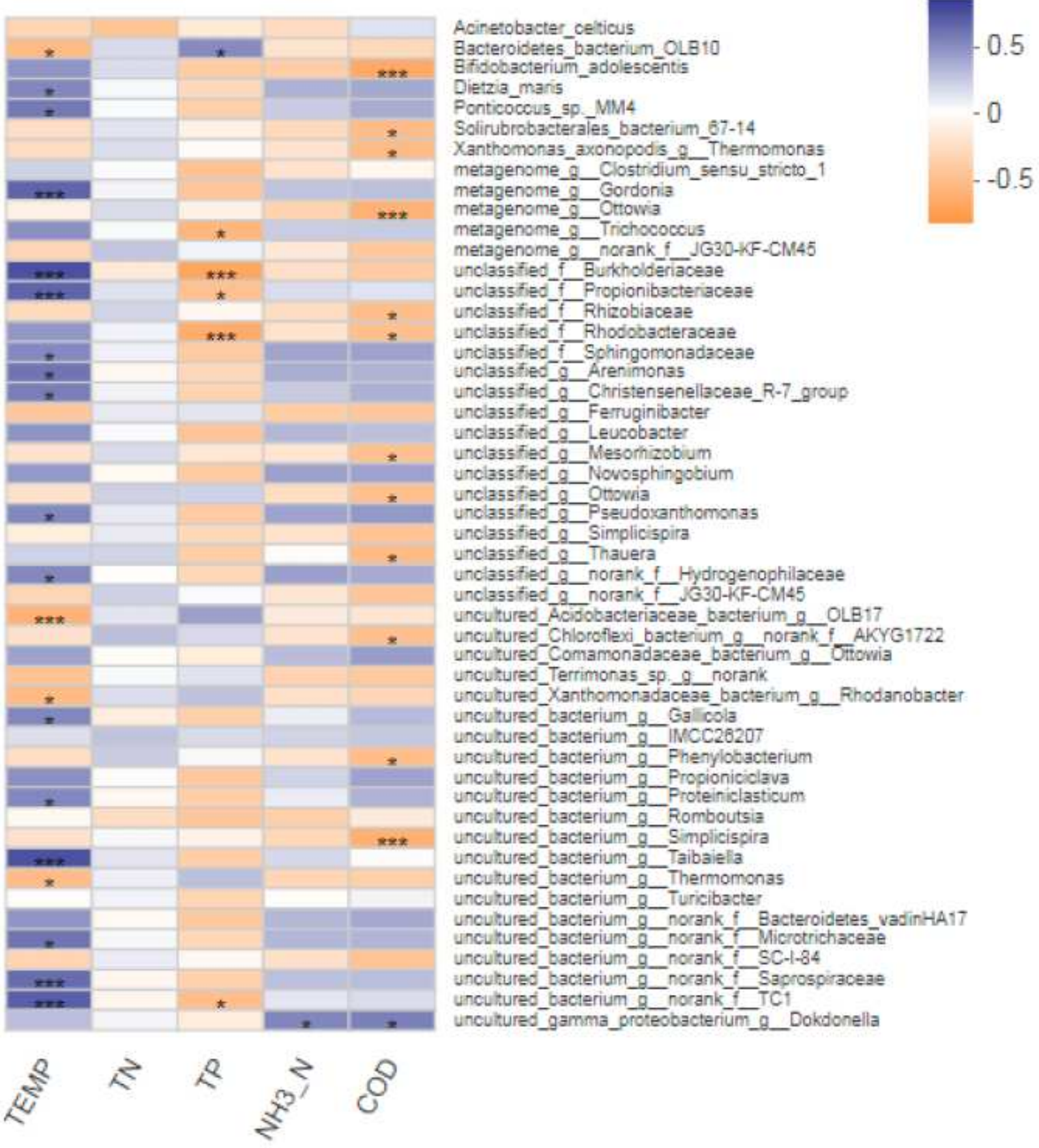

Figure 9

Correlation Heatmap. 